\title{
Barrier Effect of the Indo-Pacific Maritime Continent on MJO Propagation in Observations and CMIP5 Models
}

\author{
GUIWAN CHEN \\ State Key Laboratory of Numerical Modelling for Atmospheric Sciences and Geophysical Fluid Dynamics, Institute of \\ Atmospheric Physics, and University of Chinese Academy of Sciences, Chinese Academy of Sciences, Beijing, China, and \\ Department of Atmospheric Sciences, University of Washington, Seattle, Washington
}

\section{JIAN LING}

State Key Laboratory of Numerical Modelling for Atmospheric Sciences and Geophysical Fluid Dynamics, Institute of Atmospheric Physics, and University of Chinese Academy of Sciences, Chinese Academy of Sciences, Beijing, China

\section{CHONGYIN LI}

State Key Laboratory of Numerical Modelling for Atmospheric Sciences and Geophysical Fluid Dynamics, Institute of Atmospheric Physics, Chinese Academy of Sciences, Beijing, China

\section{YUANWEN ZHANG}

State Key Laboratory of Numerical Modelling for Atmospheric Sciences and Geophysical Fluid Dynamics, Institute of Atmospheric Physics, and University of Chinese Academy of Sciences, Chinese Academy of Sciences, Beijing, China, and Department of Atmospheric Sciences, University of Washington, Seattle, Washington

\section{CHIDONG ZHANG}

NOAA/Pacific Marine Environmental Laboratory, Seattle, Washington

(Manuscript received 14 October 2019, in final form 26 March 2020)

\begin{abstract}
This study explores possible mechanisms for the barrier effect of the Indo-Pacific Maritime Continent (MC) on MJO propagation. In particular, this study examines whether similar mechanisms can be found in both observations and CMIP5 simulations. All models simulate individual MJO events but underestimate the percentage of MJO events propagating into the MC. The simulations are grouped into the top and bottom $50 \%$ based on their capability of reproducing the MJO spectral signal. When compared with the observations, the bottom $50 \%$ of the simulations significantly underestimate the MJO strength and exaggerate the barrier effect intensity, whereas these discrepancies are not significant in the top $50 \%$ of the simulations. From the top $50 \%$ of the simulations, the MJO strength, moisture processes, and surface evaporation in the MC all play important roles in constituting the barrier effect. No such evidence is found in observations. The discrepancies may come from small observed sample size and/or misrepresentations of key physical processes in the models. A consistent result is found in the observations and simulations: Whether MJO events can cross the MC depends on the degree to which dominant precipitation over land shifts to over water in the MC as MJO convection centers approach the $\mathrm{MC}$ and cross it. This result emphasizes the critical role of precipitation over water in carrying convective signals of the MJO through the MC. The results suggest that diagnosing the model alone on mechanisms for the barrier effect could be misleading; further investigations using a combination of observations, global gridded data, and high-resolution models are needed.
\end{abstract}

\section{Introduction}

The Madden-Julian oscillation (MJO; Madden and Julian 1971, 1972), a dominant intraseasonal variability in the tropics, is characterized by a slowly eastward-propagating 
convection coupled with a large-scale circulation system. Statistically, convection of the MJO usually forms over the Indian Ocean and disappears over the central Pacific Ocean (Zhang 2005). However, for each individual MJO event, their eastward propagation of convection is often blocked by the Indo-Pacific "Maritime Continent" (MC), which is known as the barrier effect on MJO propagation (Kim et al. 2014; Zhang and Ling 2017). Many global impacts of the MJO depend on whether its convection center can move across the MC (Zhang 2013). The MC can be a choke point that limits numerical prediction skill of the MJO (Vitart et al. 2007; Kim et al. 2018; Wang et al. 2019).

The reasons for the barrier effect on MJO propagation and the mechanism for overcoming it are unclear even though they have been investigated through observational analysis and numerical modeling. Several possible mechanisms for the barrier effect have been proposed. However, without a countermechanism for overcoming the barrier effect, whatever it might be, a proposed mechanism for the barrier effect is incomplete. Here, we discuss possible mechanisms for the barrier effect along with its overcoming mechanism.

The most profound feature of the MC is its mixture of water and land, with elevated terrain on some of its islands. It is natural to think that the land and elevated terrain, which are absent from the open water of the Indian and Pacific Oceans, may affect the MJO. Surface evaporation is reduced, and surface friction is enhanced by the presence of land. If surface evaporation is critical to the MJO, then its reduction by land would lead to a barrier effect (Maloney and Sobel 2004; Sobel et al. 2008, 2010). Low-level circulations can be affected by elevated terrain (Wu and Hsu 2009) and enhanced surface friction (Wang and Sobel 2017) over the MC. If low-level circulations are important to the MJO, for example, through its advection of moisture (Kim et al. 2014; Feng et al. 2015; Kim et al. 2017; Wang et al. 2017), then their distortion by elevated terrain and enhanced surface friction would cause the barrier effect (Hsu and Lee 2005; Inness and Slingo 2006; Wu and Hsu 2009). Land and elevated terrain are perpetual fixtures of the MC. Their impacts on barrier effect alone do not explain why some MJO events propagate through the MC and others do not (Zhang and Ling 2017). A possible mechanism for overcoming the barrier effects of reduced surface evaporation and distorted low-level circulations by the presence of land is the strength of the MJO. Strong MJO events may still suffer from these barrier effects but to a lesser degree than weak ones.

Another proposed mechanism for the barrier effect is strong diurnal convection over land in MC. In a Maritime Continent convective diurnal cycle (MAC3) mechanism (Ling et al. 2019a), strong diurnal convection over land may prevent convective precipitation over water from being fully developed. This would block the MJO from crossing the MC because convective signals of MJO propagation through the MC are mainly over water (Zhang and Ling 2017). The countermechanism for overcoming this barrier effect would be weakening land diurnal convection (Neale and Slingo 2003; Wang et al. 2015; Hagos et al. 2016). This may be achieved by increases in cloud coverage and/or soil moisture (Ling et al. 2019a).

These three possible mechanisms for the barrier effect, namely, reduced surface evaporation, distorted low-level circulations, and strong diurnal convection over land, are uniquely associated with the MC and are not present anywhere else in the Indo-Pacific warm pool region. They are intrinsic mechanisms for the barrier effect. There are other possible mechanisms for the barrier effect related to atmospheric or oceanic variability. Large-scale suppressed convection over the western Pacific could promote the eastward propagation of MJO across the MC (Kim et al. 2014). Dry anomalies brought by westward-propagating synoptic disturbances from the central-western Pacific could disrupt the eastward propagation of MJO over the MC (Feng et al. 2015; DeMott et al. 2018). The intraseasonal sea surface temperature (SST) induced by the MJO (Krishnamurti et al. 1988; Zhang 1996; Shinoda et al. 1998) was suggested to be important for MJO propagation across the MC (e.g., Hirata et al. 2013; Zhu et al. 2017). Background SST over the western-central Pacific modulated by ENSO could impact the MJO propagation over the MC (Kerns and Chen 2016; DeMott et al. 2018; Suematsu and Miura 2018). SST anomalies in the MC region may also affect MJO propagation (Zhang and Ling 2017; Zhou and Murtugudde 2020). No overcoming mechanisms are needed for this type of incidental mechanisms for the barrier effect, as long as they are not associated with specific features of the MC.

Proving or disproving these proposed mechanisms for the barrier effect is difficult. Numerical models are known to suffer systematic biases in the MC region (Neale and Slingo 2003; Yang et al. 2019), indicating deficiencies in their representations of physical processes that might be key to the mechanisms for the barrier effect. Numerical experiments that artificially remove a certain process deemed essential to the barrier effect are very informative (Hagos et al. 2016; Tseng et al. 2017; Tan et al. 2020), but their results need to be confirmed by observations. The extent to which the results depend on a particular model configuration has to be assessed through duplications of same experiment by 
different models. Global data assimilation products are powerful tools for diagnosing large-scale processes, but they are not well constrained by observations in the data-sparse or vacant areas (Oliver 2016). With these limitations, a good practice in studying the barrier effect of the MC is to seek consistency among all available data from observations, their assimilation products, and numerical model simulations. In this study, we followed this principle to a certain degree.

This study investigated mechanisms for the barrier effect through comparing observations from various sources and simulations by phase 5 of the Coupled Model Intercomparison Project (CMIP5) models. There have been many studies diagnosing CMIP5 simulations for various purposes. To the best of our knowledge, there have been none on the barrier effect of the MC. Based on 20-yr simulations from five models that produce sufficient individual $\mathrm{MJO}$ events from the MJO Task Force (MJOTF) and the GEWEX Atmospheric System Study (GASS) (MJOTF/GASS; Jiang et al. 2015), Ling et al. (2019b) suggested that eastward propagation of the $\mathrm{MJO}$ is promoted by strong low-level premoistening east of the MJO convection center over the MC, which is mainly attributed to zonal gradient of low-level easterly anomalies. It is necessary to document the possible mechanisms for the barrier effect in CMIP5 simulations with longer periods and to see whether they are consistent with the observations. This would help set a benchmark to measure the progress of global coupled climate models when CMIP6 output is fully released and lead to a better understanding of the mechanisms for the barrier effect of the MC on MJO propagation.

The objective of this study is to see whether the CMIP5 simulations can reproduce the observed barrier effect intensity and to what extent evidence for the proposed mechanisms of the barrier effect and their overcoming mechanisms can be found in both observations and simulations. Given the limitations of the available data, not all aspects of the proposed mechanisms of the barrier effect can be adequately examined. We focused on the following ones:

For the intrinsic mechanisms of the barrier effect related to reduced surface evaporation by land (Maloney and Sobel 2004; Sobel et al. 2008, 2010) and distorted low-level circulations by elevated terrain and enhanced surface friction (Hsu and Lee 2005; Inness and Slingo 2006; Wu and Hsu 2009), we seek evidence of differences in surface latent heat flux and low-level wind between MJO events that cross the MC (MJO-C) and those that are blocked by the MC (MJO-B). A difference in the strength of these two types of MJO events when their convection centers over the Indian Ocean approach the MC would also be desirable evidence for these two possible mechanisms for the barrier effect. Chen and Wang (2018) proposed that eastward propagation of the MJO critically depends on its front Walker cell, which should be taken as a measure of the strength of the MJO in addition to its precipitation. The possible intrinsic mechanism of the barrier effect related to strong land diurnal convection and its overcoming mechanism in terms of soil moisture (Ling et al. 2019a) cannot be examined here because there is no diurnal and soil moisture output from CMIP5, and the models struggle with realistically simulating diurnal cycle over the MC land (Neale and Slingo 2003; Love et al. 2011; Gianotti et al. 2012; Ruppert and Hohenegger 2018; Yang et al. 2019). However, one of its critical aspects, distributions of precipitation over land and water, can be examined (Ling et al. 2019b). Evidence for the incidental mechanisms of the barrier effect related to dry anomalies (Kim et al. 2014; Feng et al. 2015; DeMott et al. 2018) and SST variabilities (Hirata et al. 2013; Zhu et al. 2017; Suematsu and Miura 2018; Zhang and Ling 2017; Zhou and Murtugudde 2020) would be differences in spatial distribution of these key variables between MJO-C and MJO-B events.

The data and method used in this study are introduced in section 2. Basic MJO features from observations and the simulations are compared to document their major discrepancies in section 3. Evidence for the proposed mechanisms for the barrier effect is examined through comparing MJO-C and MJO-B events in section 4. Further discussion is given in section 5 .

\section{Data and method}

\section{a. Models and validation datasets}

Simulations of 24 CMIP5 models (Table 1) were diagnosed in this study. The simulations are historical runs with daily outputs and cover the period of 1950-2005. Taylor et al. (2012) provided detailed information of the models and the experiment design.

Multiple observational datasets used in this study cover a shorter period of 1998-2015. Daily precipitation $\left(0.25^{\circ} \times 0.25^{\circ}\right)$ from Tropical Rainfall Measuring Mission (TRMM) 3B42, version 7, Multisatellite Precipitation Analysis (TMPA; Huffman et al. 2007) was used to identify the MJO events in the observations. Daily specific humidity, zonal, meridional, and vertical velocities $\left(0.75^{\circ} \times 0.75^{\circ}\right)$ are from the European Centre for Medium-Range Weather Forecasts interim reanalysis (ERA-Interim, hereinafter ERA-I; Dee et al. 2011). Daily surface latent heat fluxes and surface zonal wind are from objectively analyzed air-sea fluxes 
TABLE 1. Models used in this study. Model and institutional expansions can be found online (https://www.ametsoc.org/ PubsAcronymList). NIES is the National Institute for Environmental Studies. THU is Tsinghua University.

\begin{tabular}{lllr}
\hline \hline & \multicolumn{1}{c}{ Model } & \multicolumn{1}{c}{ Institute } & Spatial resolution (lon $\times$ lat; $\left.{ }^{\circ}\right)$ \\
\hline 1 & ACCESS1.0 & CSIRO and BoM, Australia & $1.875 \times 1.25$ \\
2 & ACCESS1.3 & CSIRO and BoM, Australia & $1.875 \times 1.25$ \\
3 & CanESM2 & CCCma, Canada & $2.81 \times 2.79$ \\
4 & CMCC-CESM & CMCC, Italy & $3.75 \times 3.44$ \\
5 & CMCC-CM & CMCC, Italy & $0.75 \times 0.75$ \\
6 & CMCC-CMS & CMCC, Italy & $3.75 \times 3.71$ \\
7 & CNRM-CM5 & CNRM and CERFACS, France & $1.41 \times 1.40$ \\
8 & FGOALS-g2 & IAP and THU, China & $2.81 \times 2.79$ \\
9 & FGOALS-s2 & IAP, China & $2.81 \times 1.66$ \\
10 & GFDL CM3 & NOAA GFDL, United States & $2.5 \times 2.0$ \\
11 & GFDL-ESM2G & NOAA GFDL, United States & $2.5 \times 2.0$ \\
12 & IPSL-CM5A-LR & IPSL, France & $3.75 \times 1.89$ \\
13 & IPSL-CM5A-MR & IPSL, France & $2.5 \times 1.27$ \\
14 & IPSL-CM5B-LR & IPSL, France & $3.75 \times 1.89$ \\
15 & MIROC4h & AORI, NIES, JAMSTEC, Japan & $0.56 \times 0.56$ \\
16 & MIROC5 & AORI, NIES, JAMSTEC, Japan & $1.41 \times 1.40$ \\
17 & MIROC-ESM & AORI, NIES, JAMSTEC, Japan & $2.81 \times 2.79$ \\
18 & MIROC-ESM-CHEM & AORI, NIES, JAMSTEC, Japan & $2.81 \times 2.79$ \\
19 & MPI-ESM-LR & MPI, Germany & $1.875 \times 1.87$ \\
20 & MPI-ESM-MR & MPI, Germany & $1.875 \times 1.87$ \\
21 & MPI-ESM-P & MPI, Germany & $1.875 \times 1.87$ \\
22 & MRI-CGCM3 & MRI, Japan & $1.125 \times 1.12$ \\
23 & MRI-ESM1 & MRI, Japan & $1.125 \times 1.12$ \\
24 & NorESM1-M & Norwegian Climate Centre & $2.5 \times 1.89$ \\
\hline
\end{tabular}

(OAFlux; Yu et al. 2008) available at a horizonal resolution of $1^{\circ}$. Daily SST is from the National Oceanic and Atmospheric Administration (NOAA) Optimum Interpolated Sea Surface Temperature (OISST; Reynolds et al. 2007) dataset with a spatial resolution of $0.25^{\circ}$.

All datasets used were interpolated into the same horizontal grids $\left(2.5^{\circ} \times 2.5^{\circ}\right)$, following the MJOTF/ GASS project (Jiang et al. 2015) for a fair comparison. The analysis covers October-March when the MJO is strong. It is noted that the time coverage of the simulations $(56 \mathrm{yr})$ is longer than that of the observations $(18 \mathrm{yr})$. To eliminate the influence of the time coverage, all the diagnostics for the simulations were repeated for a shorter duration (1988-2005) to match the observations. The results are the same.

\section{b. Method}

For a given variable, its daily anomalies were obtained by removing its climatological seasonal cycle (omitting 29 February in leap years). A two-dimensional time-space fast Fourier transform was then applied to obtain the large-scale (zonal wavenumbers $0-6$ ) and intraseasonal (20-100 days) signals of the MJO (Wheeler and Kiladis 1999). Both eastward- and westward-propagating signals were retained. The westward-propagating signals could be comparable to or even stronger than the eastward-propagating signals in some models (Zhang et al. 2006; Jiang et al. 2015); therefore, retaining only eastward-propagating signals would artificially enhance the eastward-propagation ability of MJO in some simulations and then overestimate the number of MJO identified.

The MJO events in this study are represented by large-scale positive precipitation anomalies in the tropics that propagate eastward for at least $50^{\circ}$ in longitude. They were identified using an MJO tracking method proposed by Ling et al. (2014) and modified by Zhang and Ling (2017). This method tracks the latitudinally averaged $\left(15^{\circ} \mathrm{S}-15^{\circ} \mathrm{N}\right)$ eastward-propagating positive precipitation anomalies. It provides specific quantities that measure the characteristics (e.g., starting and ending longitudes, speed, strength, propagating ranges, and life-spans) of identified MJO events that are not available from EOF-based MJO indices (Wheeler and Hendon 2004; Kiladis et al. 2014; Liu et al. 2016). The longitudinal location of MJO convection cannot be precisely identified by the commonly used real-time multivariate MJO index (RMM; Wheeler and Hendon 2004) that is based on global tropical coherent patterns of convection and circulations; the contributions from convection are generally much less than the circulation in RMM (Straub 2013; Liu et al. 2016; Zhang and Ling 2017). 
Following Zhang and Ling (2017), we grouped the MJO events into those that cross the MC with their ending longitudes east of $150^{\circ} \mathrm{E}$ (MJO-C) and those that are blocked by the $\mathrm{MC}$ with their ending longitudes west of $150^{\circ} \mathrm{E}$ (MJO-B). Issues related to the barrier effect of the $\mathrm{MC}$ can be adequately addressed only by comparing these two types of MJO events. For the composites and their differences, the Student's $t$ test was applied to assess their significance. Composites of wind vectors are considered significant if either one component passes the Student's $t$ test. When comparing two probability density distributions, a Kolmogorov-Smirnov (KS) test was used to assess whether their differences are significant. The word "significant" is used in this study only if results pass the test at the $95 \%$ confidence level.

Conventional diagnostics of MJO simulations by multiple models compare the multimodel mean of "good" versus that of "bad" models in terms of MJO statistics they produced. In this study, we took a different approach first applied by Ling et al. (2019b). We treated simulations as a superensemble and all identified MJO events from these simulations as simulated $\mathrm{MJO}$ events without attaching them to the individual models that produced them. Comparisons were made between observed and simulated MJO events.

One advantage of the superensemble approach is that we move away from comparing individual models with the observations or comparing good versus bad models, which allows us to focus on identifying issues that may apply to most, if not all, models. Another advantage of this approach is that the significance for differences between MJO-B and MJO-C can be directly accessed, which is difficult using multimodel mean.

A potential risk of this superensemble approach is that diagnosed biases may come from a fraction of the models and, if so, any generalization based on the superensemble approach would be misleading. To avoid this, the evaluation for each individual model was conducted to check whether their results agree with that from the superensemble approach.

\section{Statistics of observed and simulated MJO events}

It is well known that the observed spectral signal of the MJO is represented by a spectral peak of precipitation or its proxy (such as outgoing longwave radiation) at positive (eastward) intraseasonal frequencies and planetary zonal scale that is separated from the stationary peak centered at frequency 0 (Fig. 1a). The eastward propagation of the MJO is indicated by a large difference between this MJO signal and its much weaker counterpart at negative (westward) frequencies. Their ratio has been used to measure the strength of the MJO

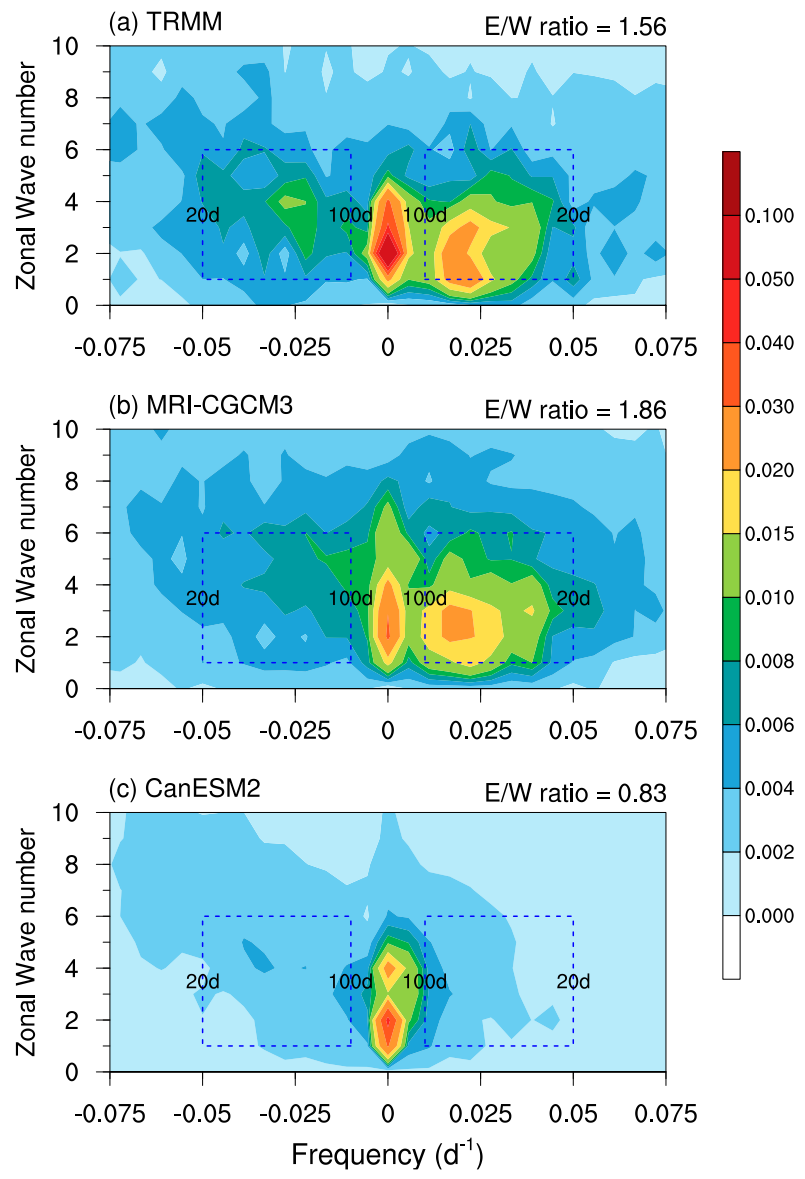

FIG. 1. Annual mean wavenumber-frequency power spectra of precipitation anomalies averaged over $15^{\circ} \mathrm{S}-15^{\circ} \mathrm{N}$ from (a) TRMM and simulations by (b) MRI-CGCM3 and (c) CanESM2 during October-March. The dash-outlined boxes mark the intraseasonal (20-100 days) and planetary $(k=1-6)$ domains used in calculating eastward vs westward power ratios.

spectral signal in observations (Zhang and Hendon 1997) and in simulations (Zhang et al. 2006; Hung et al. 2013; Ahn et al. 2017). In this study, the ratio was calculated for spectral domains of (positive and negative) periods of 20-100 days and zonal wavenumbers 1-6 (dashed boxes in Fig. 1).

It is also well known that the observed MJO spectral signals can be reproduced by some modern global climate models but not by others (Hung et al. 2013; Jiang et al. 2015; Ahn et al. 2017). This is indeed the case for the CMIP5 models diagnosed here. It is interesting to see that some simulations produced the spectral ratios close to the observed whereas others produced lower ratios (abscissa in Fig. 2). An example of the "overachievers" is given in Fig. 1b, where the MJO spectral signal unambiguously exists. An example of the "underachievers" is given in Fig. 1c, where the MJO spectral signal is completely missing. As discussed in section 2, 


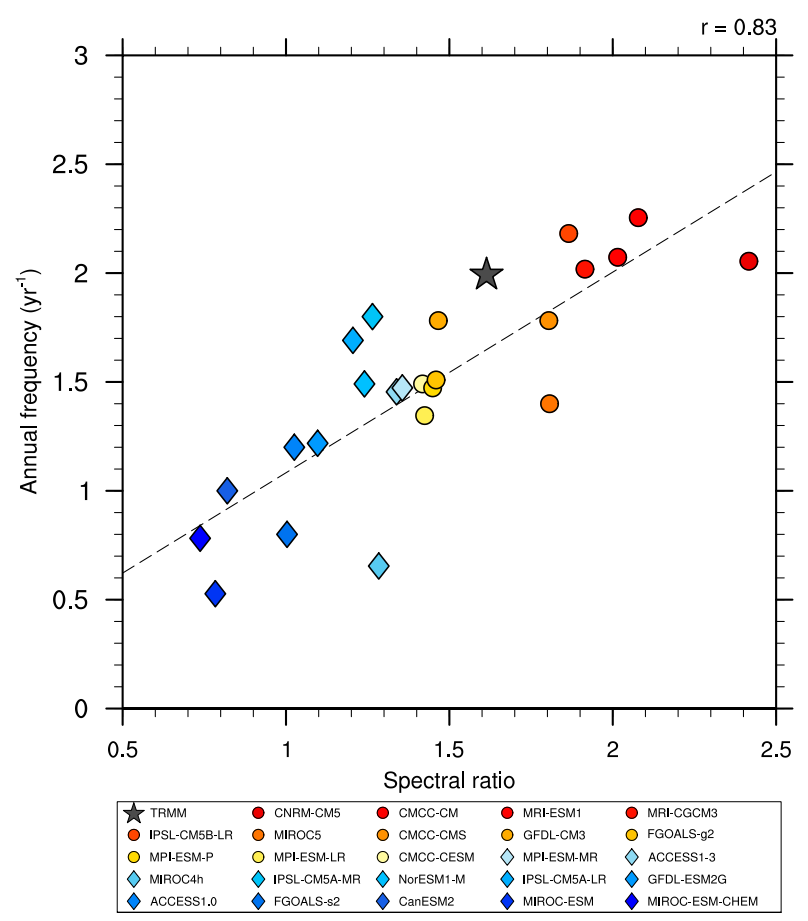

FIG. 2. Scatterplots of ratios between eastward and westward spectral power within zonal wavenumbers 1-6 and periods of 20 100 days of the precipitation anomalies averaged over $15^{\circ} \mathrm{S}-15^{\circ} \mathrm{N}$ (abscissa) and annual frequencies (ordinate) of MJO events identified during October-March in TRMM and the simulations. The black pentagram represents TRMM, circles in red hues represent the top $50 \%$ of the simulations, and diamonds in blue hues represent the bottom $50 \%$ of the simulations.

underachievers can still produce MJO events, but they do so infrequently. Figure 2 also demonstrates the connection between the model capability of reproducing the observed spectral signals (abscissa) and frequency (ordinate) of the MJO first revealed by Ling et al. (2017). Most models underestimate the MJO frequency, especially those that produce very small spectral ratios (blue diamonds in Fig. 2). There is a significant correlation $(0.83)$ between the spectral ratio and annual frequency of the MJO from the simulations. The simulations are grouped into the "top 50\%" that can reproduce the observed spectral ratio (circles in Fig. 2), and the "bottom 50\%" that struggle to reproduce the observed MJO spectral signal (diamonds in Fig. 2).

The total sample sizes of identified MJO events during October-March are very different from TRMM (34) and the simulations (1950). Their fair comparison would be the annual frequency (number of MJO per year). It is about $26 \%$ lower in the simulations than in TRMM. Because the subject of this study is the barrier effect of the $\mathrm{MC}$, we only include the $\mathrm{MJO}$ events that propagate from the Indian Ocean (initiated west of $90^{\circ} \mathrm{E}$ ) and pass through $100^{\circ} \mathrm{E}$ into the $\mathrm{MC}$ in the following analysis. The numbers of identified events meeting the criteria are 27 in the observations and 1094 in the simulations. These MJO events are $79 \%$ of all identified in TRMM and $54 \%$ in the simulations (Table 2). This lower (by onequarter) fraction of $\mathrm{MJO}$ events initiated west of $90^{\circ} \mathrm{E}$ in the simulation is a measure of the misrepresentation of MJO starting longitudes by the models suggested by Ling et al. (2017). Both the top and bottom 50\% of the simulations underestimate the percentage of MJO propagating into the $\mathrm{MC}$ (Table 2 ).

On average, observed and simulated MJO events show similar features of eastward propagation (Fig. 3). The main difference is their longitudinal coverage. MJO events propagate to the date line in TRMM (Fig. 3a), whereas they become very weak over the western Pacific (east of $160^{\circ} \mathrm{E}$ ) in the simulations (Fig. 3b). This difference may be an indicator of the exaggerated barrier effect of the MC in the simulations. This will be further quantified. The MJO events in the bottom $50 \%$ of the simulations show much weaker amplitude and shorter longitudinal coverage (Fig. 3d). The longitudinal coverage of the $\mathrm{MJO}$ in the top $50 \%$ of the simulations also deviated from the observations but to a lesser degree (Fig. 3c). Another visible difference is over the Indian Ocean: strong eastward negative precipitation anomalies precede positive anomalies in TRMM, which is not present in the simulations. As will be demonstrated later, MJO initiation over the Indian Ocean is a major discrepancy between the observations and simulations.

The barrier effect intensity can be quantified by the ratio of the total number of MJO-B versus that of MJO-C. There are 14 MJO-B and 13 MJO-C identified in TRMM while $632 \mathrm{MJO}-\mathrm{B}$ and $462 \mathrm{MJO}-\mathrm{C}$ in the simulations. Both the annual frequencies of MJO-B and MJO-C are underestimated in the simulations, but this underestimation in annual frequency is more obvious for MJO-C: The annual frequency of MJO-B events in the simulations is $41 \%$ lower than that in TRMM, and it is $58 \%$ lower for MJO-C (Table 2). As a result, the ratio of the total number of MJO-B versus that of MJO-C is 1.48 in the simulations, which is higher than that in TRMM (1.08) (Table 2). This higher ratio implies the exaggerated barrier effect intensity in the simulations, which is mainly contributed by the bottom $50 \%$ of the simulations (2.72).

To further quantify possible discrepancies between the observed and simulated MJO events, distributions of frequencies for their certain parameters are compared (Fig. 4). The propagating characteristics of identified MJO events are different between the top and bottom $50 \%$ of the simulations (Figs. 3c,d). Here we group all simulated MJO events into those produced by the top and bottom $50 \%$ of the simulations. As found previously 
TABLE 2. Statistics of MJO events in TRMM and the simulations.

\begin{tabular}{lcccc}
\hline & TRMM & All simulations & Top 50\% of the simulations & Bottom 50\% of the simulations \\
\hline $\begin{array}{l}\text { Percentage of MJO that propagate into } \\
\text { the MC }\end{array}$ & 79 & 54 & 57 & 49 \\
Annual frequency & & & & 0.53 \\
$\quad$ MJO-B & 0.82 & 0.48 & 0.49 & 0.42 \\
$\quad$ MJO-C & 0.76 & 0.32 & $1.09(352 / 323)$ & 2.16 \\
Ratio of MJO-B/MJO-C & $1.08(14 / 13)$ & $1.48(632 / 426)$ & $280 / 103)$ \\
Avg strength (mm day $\left.{ }^{-1}\right)$ & & & 2.72 & 1.98 \\
$\quad$ MJO-B & 2.75 & 2.39 & 3.17 & 2.04 \\
MJO-C & 3.24 & 2.90 & \\
\hline
\end{tabular}

(Zhang and Ling 2017), most observed MJO events are initiated over the Indian Ocean and hence there is a dominant peak there in the distribution of MJO starting longitudes (Fig. 4a). The distributions of MJO starting longitudes from the top and bottom $50 \%$ of the simulations also peak over the Indian Ocean, but they cover a broader longitudinal range. There are two peaks for distributions of MJO ending longitudes in TRMM: one over the MC and the other over the central Pacific (Fig. 4b). This is the evidence of the MC barrier effect on MJO propagation (Zhang and Ling 2017). The peak over the central Pacific is missing in both the top and bottom $50 \%$ of the simulations. However, there is no
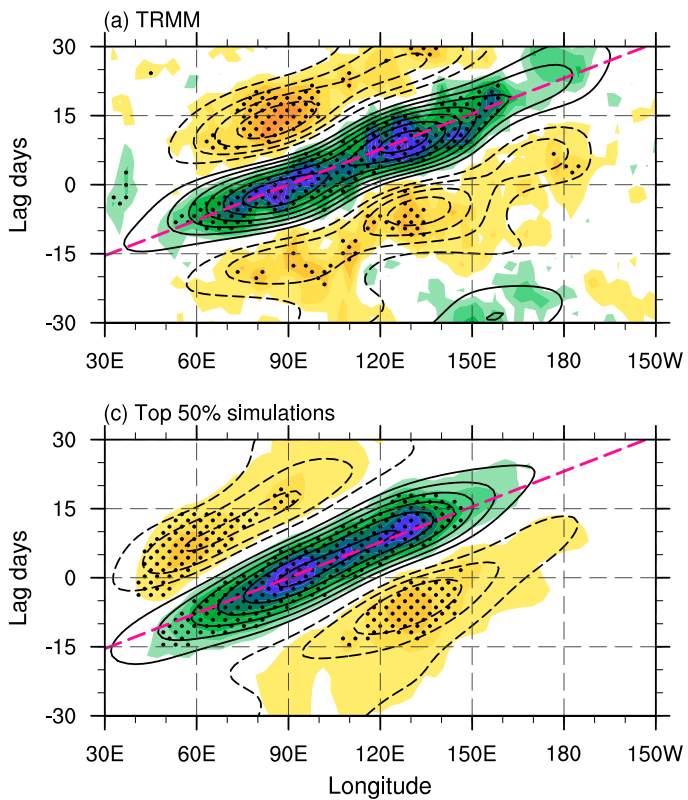

significant difference between the distributions of ending longitude for the MJO in the top $50 \%$ of the simulations and TRMM, but the differences are significant between the bottom $50 \%$ of the simulations and TRMM. This indicates the barrier effect is exaggerated in the bottom $50 \%$ of the simulations (Kim et al. 2009; Seo et al. 2009; Wang et al. 2014; Ling et al. 2019b). As a consequence of the differences in the starting and ending longitudes, there are more MJO events propagating over longer ranges in TRMM than in the simulations (Fig. 4c). The differences are, however, not significant between TRMM and the top $50 \%$ of the simulations. Interestingly, the bottom $50 \%$ of the simulations
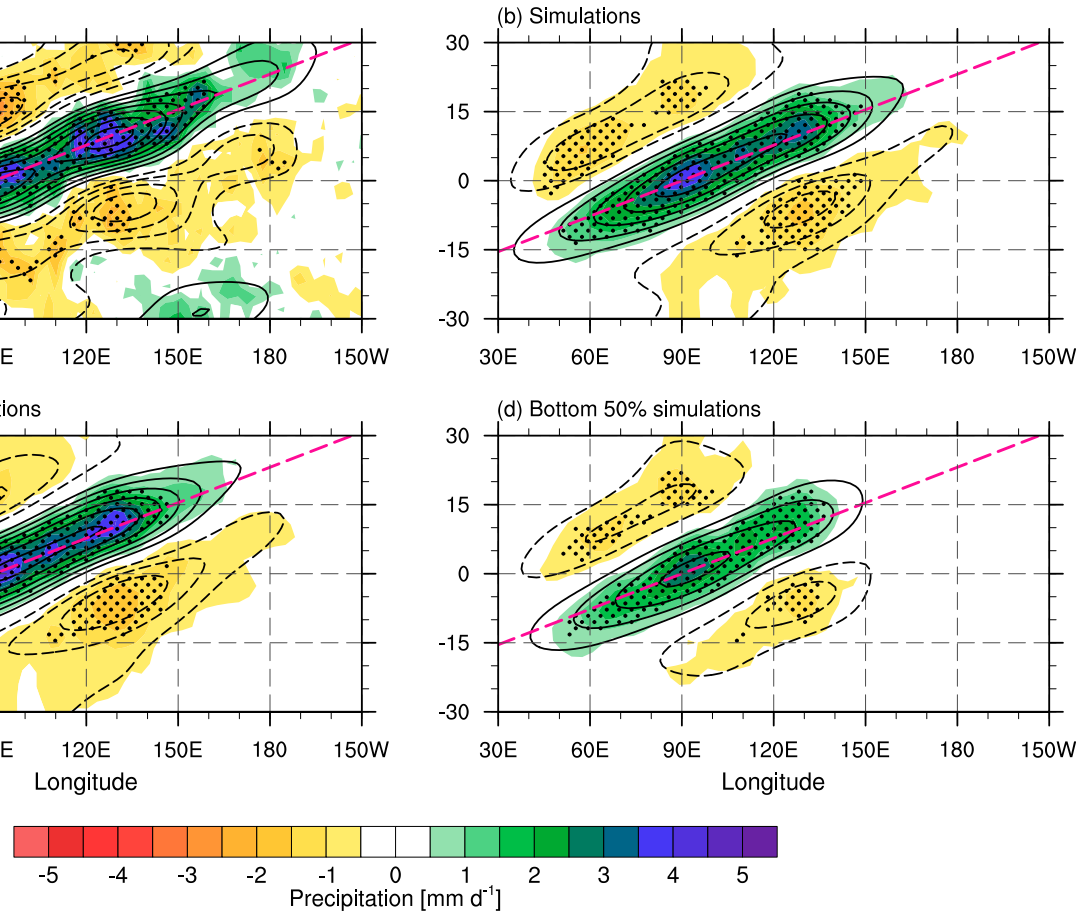

FIG. 3. Composites of time-longitude evolution of 5-day running mean (shading) and large-scale intraseasonally (zonal wavenumbers 0-6; 20-100 days) filtered daily precipitation anomalies (contours; interval of $0.5 \mathrm{~mm} \mathrm{day}^{-1}$ ) of MJO events during October-March from (a) TRMM, (b) the simulations, (c) the top $50 \%$ of the simulations, and (d) the bottom $50 \%$ of the simulations based on their spectral ratios as shown in Fig. 2. Day 0 is the day on which the tracked MJO events cross $90^{\circ} \mathrm{E}$. The dashed straight line marks the $5 \mathrm{~m} \mathrm{~s}^{-1}$ eastward propagation speed; 5-day running mean precipitation anomalies significant at the $95 \%$ confidence level are stippled. 

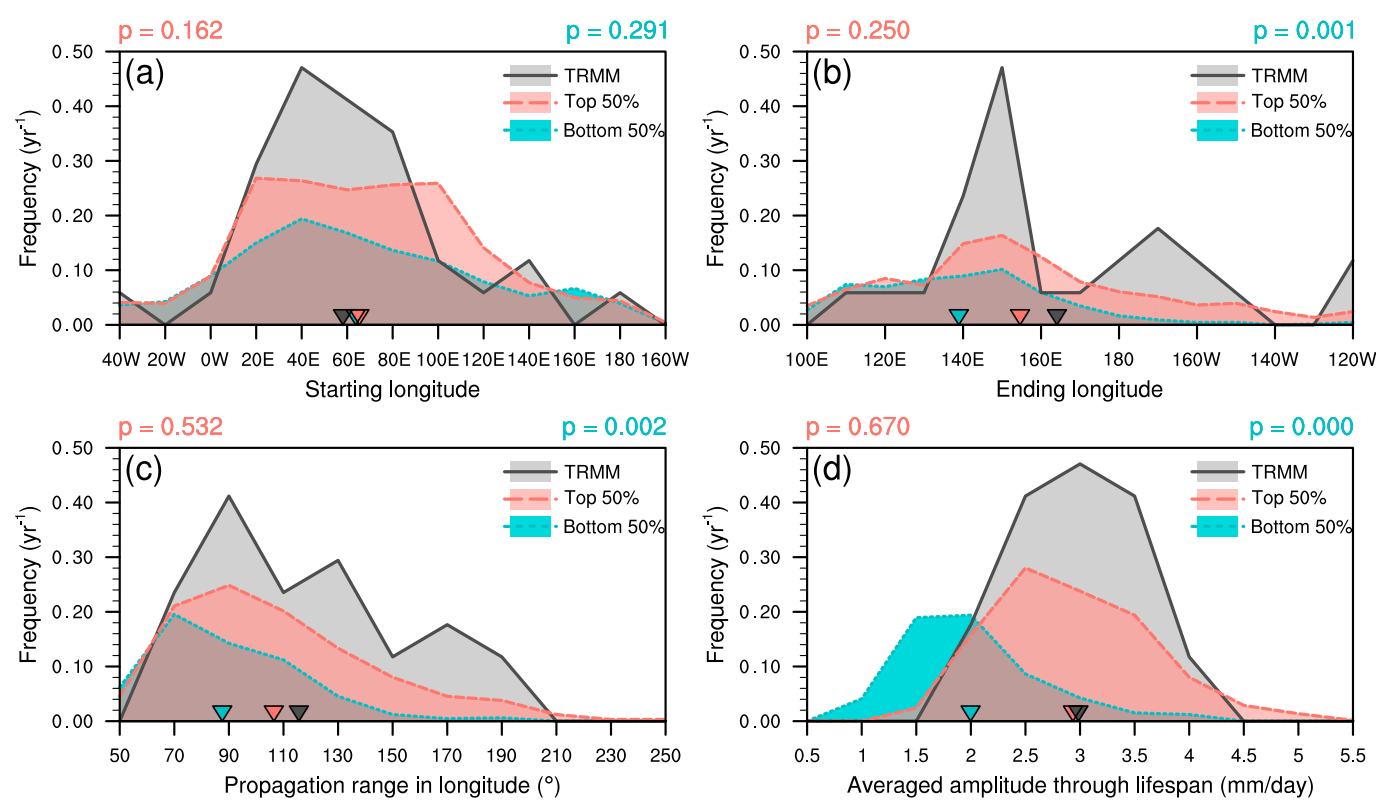

FIG. 4. Distributions of frequencies for tracked MJO characteristics in terms of (a) starting longitudes of all identified MJO events and (b) ending longitudes, (c) propagation ranges, and (d) averaged amplitudes through the entire life-span of MJO events starting west of $90^{\circ} \mathrm{E}$ in TRMM (solid black line and gray shading), the top $50 \%$ of the simulations (dashed pink line and pink shading), and the bottom $50 \%$ of the simulations (dotted blue line and blue shading) during October-March. Solid triangles mark the corresponding means. The $p$ value (pink for the top $50 \%$ of the simulations and blue for the bottom $50 \%$ of the simulations) is also given on the basis of the KS test between the simulations and TRMM.

significantly underestimate the strength of the MJO through their life-span when compared with TRMM, but the top $50 \%$ of the simulations produce a similar distribution compared with TRMM (Fig. 4d).

One risk of treating all identified MJO events as a superensemble is the differences between the simulations and the observations may come from a fraction of the models and cannot be applied to each individual model. To address this question, certain characteristics of the MJO events produced by each individual model are compared with those of the observed MJO (Fig. 5). All simulations underestimate the percentage of MJO events initiated west of $90^{\circ} \mathrm{E}$ (Fig. 5a), implying that the misrepresentation of MJO starting longitudes exists in all the models diagnosed. Taking the observed MJO events as reference, most of the bottom $50 \%$ of the simulations significantly underestimate the averaged ending longitude, propagation range, and averaged strength of the MJO, but there is no significant difference in most of the top $50 \%$ of the simulations (Figs. 5b-d). The results suggest that the MJO events produced by the top $50 \%$ of the simulations can be treated as a superensemble if we take the observations as reference.

In summary, simulated MJO events differ from the observed mainly in their frequency of entering the MC (not enough events initiated west of $90^{\circ} \mathrm{E}$ and propagatedthrough $100^{\circ} \mathrm{E}$ ), strength (too weak in the simulations), and barrier effect intensity (exaggerated in the simulations). The top $50 \%$ of the simulations produce MJO events with similar strength and barrier effect intensity as the observed, while the bottom $50 \%$ significantly underestimate the strength and exaggerated the barrier effect intensity. These results do not come from a fraction of the simulations; they commonly existed in most of the top/bottom $50 \%$ of the simulations.

\section{Possible mechanisms for the barrier effect}

In this section, we explore how well the mechanisms of the barrier effect are reproduced by the simulations. This is a difficult question because we do not know for sure what the mechanisms for the barrier effect are in reality. An appropriate way of addressing this question is to examine possible mechanisms proposed so far to the extent that they can be done using observations (see discussion in section 1). For this, we use differences between MJO-B and MJO-C events as indications of possible mechanisms, and we compare these differences between the simulations and observations.

In section 3, we showed that most of the top $50 \%$ of the simulations produce the MJO events with similar strength and barrier effect intensity as the observations. 

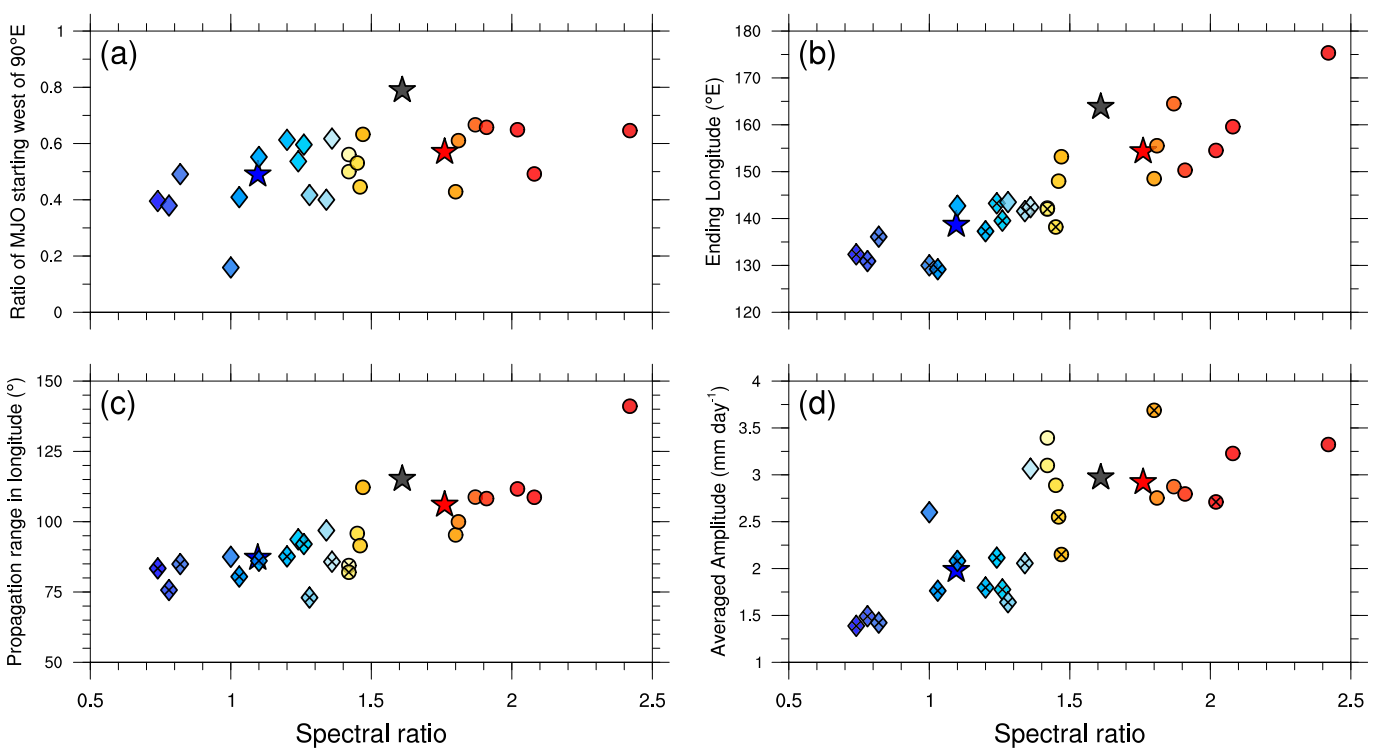

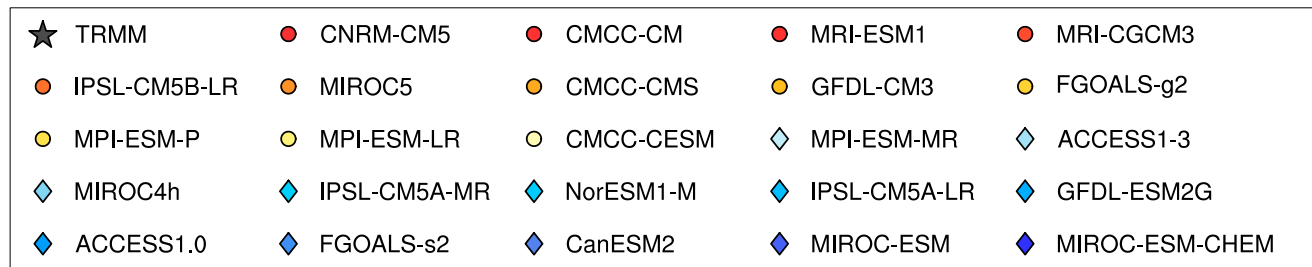

FIG. 5. Scatterplots between eastward and westward spectral power within zonal wavenumbers 1-6 and periods of $20-100$ days of the precipitation anomalies averaged over $15^{\circ} \mathrm{S}-15^{\circ} \mathrm{N}$ and (a) ratio of MJO events initiated west of $90^{\circ} \mathrm{E}$, (b) averaged ending longitude, (c) averaged propagation range in longitude, and (d) averaged amplitudes through the entire life-span in TRMM (black pentagram) and each individual simulation (colored circles for the top $50 \%$ of the simulations, and diamonds for the bottom $50 \%$ of the simulations). The red pentagram and blue pentagram mark the corresponding averaged value for MJO events in the top $50 \%$ and bottom $50 \%$ of the simulations, respectively. Crosses in (b)-(d) mark the simulations that produce the distributions of MJO features that are significantly different from that in TRMM at the $95 \%$ confidence level as based on a KS test.

A question raised is how they produce a similar barrier effect intensity as the observations because the peak of the ending longitude of their MJO over the central Pacific is missing. The results in section 3 also indicate that the bottom $50 \%$ of the simulations obviously underestimate the MJO strength and exaggerate the barrier effect intensity. Given the discrepancies of the MJO events produced by the bottom $50 \%$ of the simulations, it is inappropriate to compare the possible mechanisms of barrier effect using the bottom $50 \%$ of the simulations. Thus, in this section, we adopted only the top $50 \%$ of the simulations that can reproduce the MJO spectral signal and produce observed-like MJO events to explore whether the possible mechanisms for the barrier effect of the MC are similar in the simulations and the observations. In the following sections, all identified MJO events from the top $50 \%$ of the simulations were treated as a superensemble of simulated MJO events without attaching them to the individual models that produced them. The word "simulations" represents the top 50\% of the simulations in this section. Comparisons were made between observed and simulated MJO events.

\section{a. Amplitudes}

As discussed in section 1, strong MJO events may have better chances to overcome the intrinsic barrier effects of reduced surface evaporation and distorted low-level circulations by the presence of land. Some studies have shown such a connection (e.g., DeMott et al. 2018), but others did not (e.g., Zhang and Ling 2017). We found that the averaged strength through the life-span of MJO-C is greater than that of MJO-B in the simulations and in TRMM (Table 2). But this difference might be a result of barrier effect because the strength of MJO-B after entering the MC should be significantly weaker than that of MJO-C (Zhang and Ling 2017). To further address this question, we compare the horizontal structure of precipitation and low-level circulations 

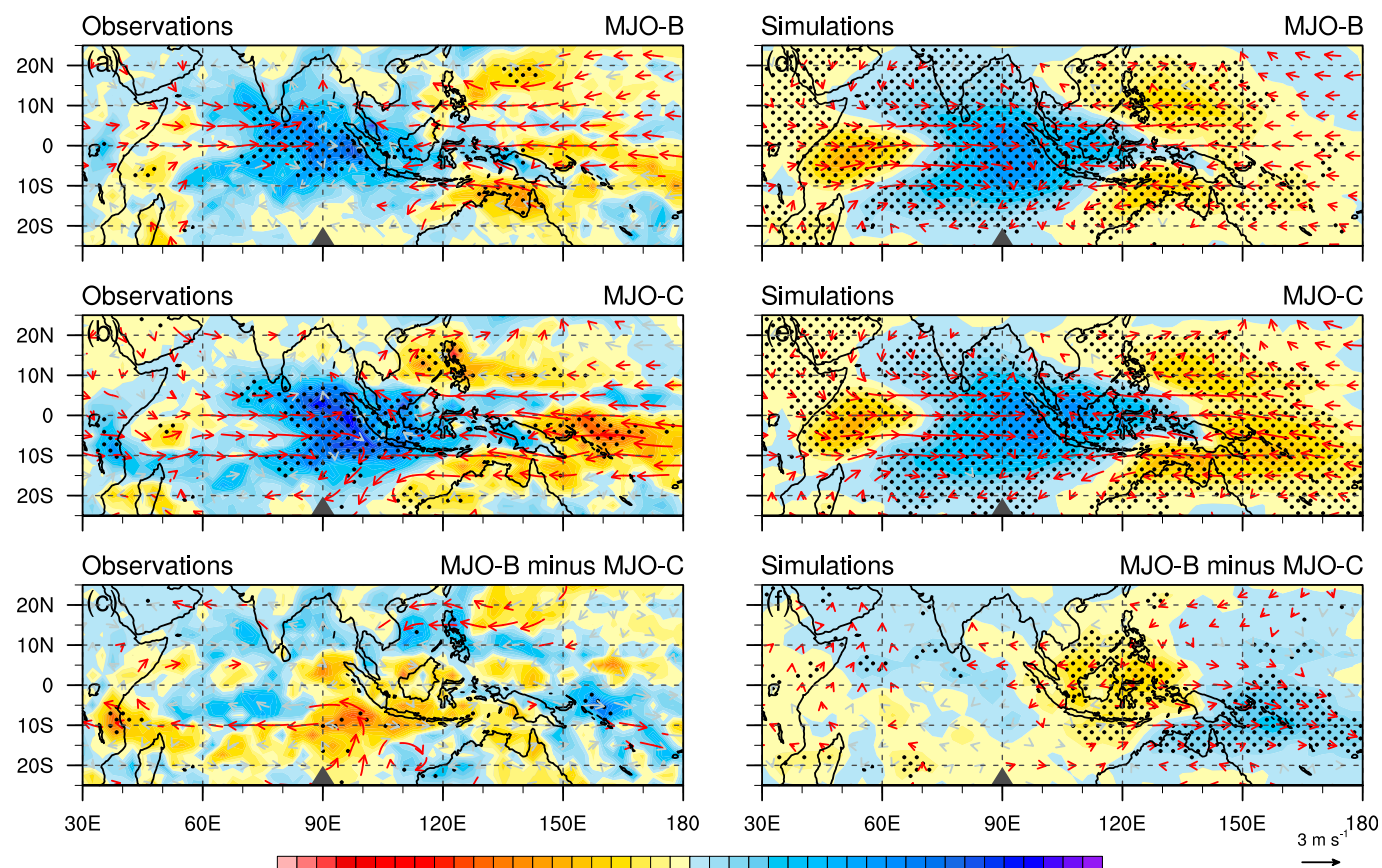

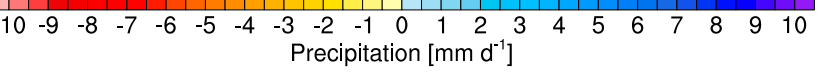

FIG. 6. Horizontal distributions of 20-100-day bandpass-filtered precipitation anomalies (shading) and 850-hPa wind vectors for (a),(d) MJO-B and (b),(e) MJO-C and (c),(f) their differences in the (left) observations and (right) simulations when $\mathrm{MJO}$ convection centers cross $90^{\circ} \mathrm{E}$ (marked by triangles). Stippling for precipitation and red vectors for wind mark results that are significant at the $95 \%$ confidence level.

between MJO-C and MJO-B when the MJO convection centers locate at $90^{\circ} \mathrm{E}$ approaching the MC (Fig. 6).

The canonical structure of the MJO (Zhang 2005) is obvious for MJO-B and MJO-C in both the observations and the simulations: there are low-level easterly (westerly) anomalies east (west) of the MJO convection (Fig. 6). The precipitation anomalies east of the convection center for MJO-C tend to be stronger than MJO-B in both the observations (Fig. 6c) and the simulations (Fig. 6f). The differences are significant in the simulations but not in the observations. These suggest that stronger MJO events may have a higher chance to propagate through the $\mathrm{MC}$, but the strength of the $\mathrm{MJO}$ is not a decisive factor for overcoming the barrier effect in the observations when the MJO convection center locates over the Indian Ocean. However, strength over Indian Ocean might be a decisive factor in the simulations. It is also interesting to note that there is stronger low-level convergence ahead of the MJO convection for MJO-C than for MJO-B in the simulations (Fig. 6f).

Apart from the precipitation, the strength of the MJO can also be measured by its front Walker cell (Chen and Wang 2018). Vertical-zonal structures of moisture and circulations between MJO-C and MJO-B in ERA-I and the simulations are compared when MJO convection centers are at $90^{\circ} \mathrm{E}$ (Fig. 7). The front Walker cells directly associated with MJO convection are obvious for both MJO-B and MJO-C events in both ERA-I and the simulations, but the differences are distinct. In ERA-I, significant differences are seen in the mid-upper troposphere west of MJO convection centers (Fig. 7c) and appear to be related to the westward tilt structure of the MJO (Sperber 2003; Kiladis et al. 2005; Adames and Wallace 2015) that is more evident for MJO-C than MJO-B (Figs. 7a,b). Previous studies have suggested that the front Walker cell could help the MJO overcome the barrier effect in the observations (Chen and Wang 2018) and in the simulations (Ling et al. 2019b). Evidence for this proposed mechanism is not found in ERA-I with no significant difference in the low-level zonal wind between MJO-C and MJO-B. Such difference exists in the simulations where the front Walker cell, including its low-level zonal wind, is significantly stronger for MJO-C than MJO-B (Fig. 7f). The differences of ascending motion and midtroposphere moisture east of the MJO convection between MJO-C and MJO-B are also significant in the simulations (Fig. 7f).

The results suggest that strength of MJO represented by both precipitation and front Walker cell is a decisive factor for overcoming the barrier effect in the simulations. 

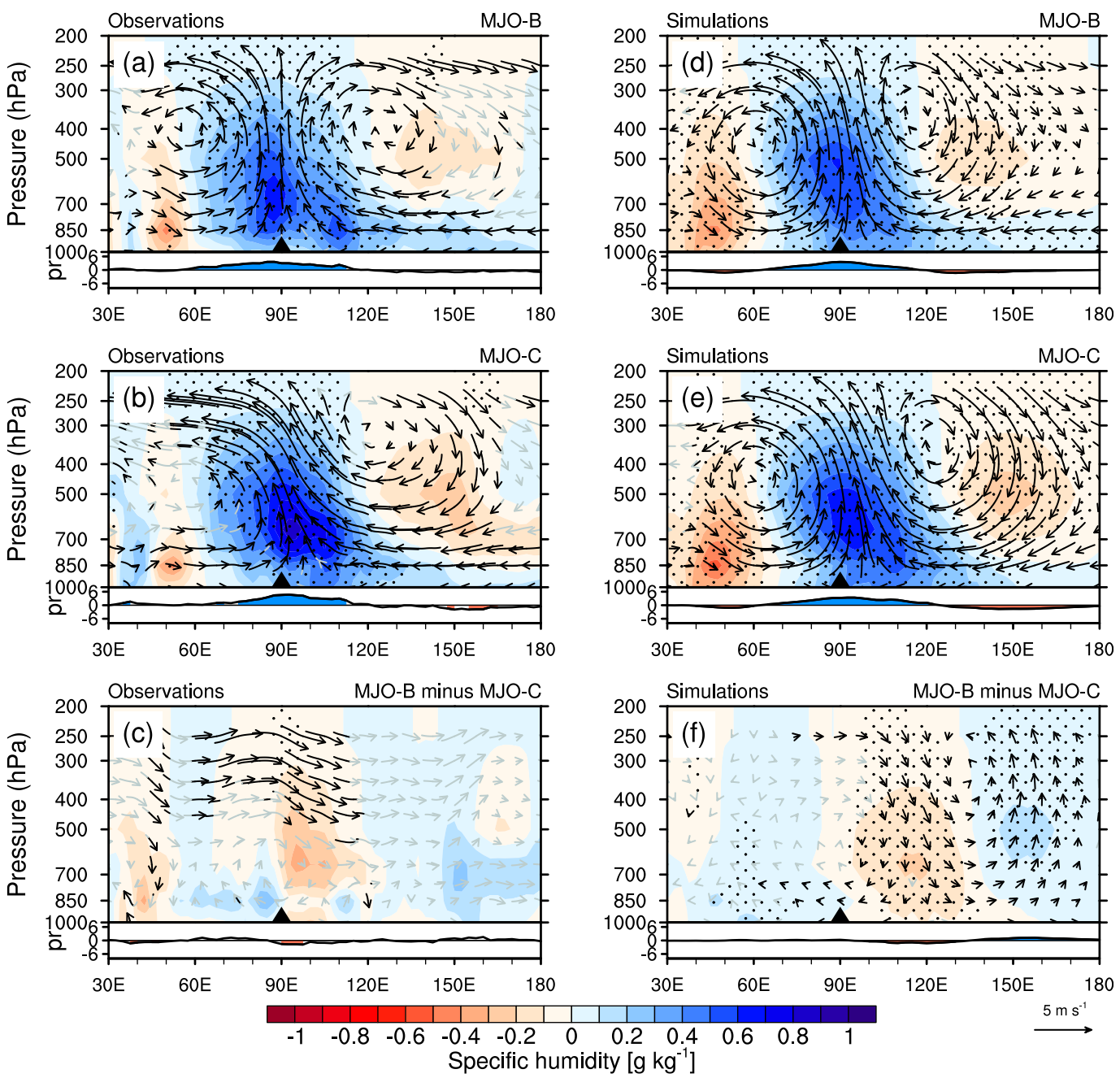

FIG. 7. Composites of vertical-zonal distributions of 20-100-day bandpass-filtered specific humidity anomalies (shadings; $\mathrm{g} \mathrm{kg}^{-1}$ ) and $u-\omega$ wind anomalies (vectors) as well as corresponding precipitation anomalies (curves) averaged over $15^{\circ} \mathrm{S}-15^{\circ} \mathrm{N}$ for (a),(d) MJO-B and (b),(e) MJO-C and (c),(f) their differences in the (left) observations and (right) simulations when $\mathrm{MJO}$ convection centers cross $90^{\circ} \mathrm{E}$ (marked by solid triangles). Vertical velocities are scaled by a factor of 100 to make them visible. Results that are significant at the $95 \%$ confidence level are marked by black arrows for wind vectors, stippling for specific humidity, and color for precipitation.

No such evidence is found in the observations. It should be noted that the results may change when the sample size (number of MJO events identified) becomes larger in the observations.

\section{b. Meridional-vertical structures}

Meridional advection of moisture from the equator has been proposed to be a key process for MJO propagation through the MC (Kim et al. 2014). To evaluate this, the meridional-vertical cross sections of circulations and moisture averaged between $100^{\circ}$ and $140^{\circ} \mathrm{E}$ when $\mathrm{MJO}$ convection centers at $90^{\circ} \mathrm{E}$ (Fig. 8) are compared over where the moisture tendency is larger (not shown).
In observations, there is a deep but narrow ascending motion east of the MJO convection center produced by boundary layer convergence that moistens the midtroposphere; off-equatorial meridional winds that transport moisture poleward from the equator around $700 \mathrm{hPa}$ are clear in MJO-C and MJO-B (Figs. 8a,b) (Kim et al. 2014; Adames and Wallace 2014, 2015). The difference is not significant between MJO-B and MJO-C except for weaker upward motion around $10^{\circ} \mathrm{S}$ in MJO-B (Fig. 8c). The simulations reproduce the general meridional-vertical structure of circulations and moisture ahead the MJO convection center (Figs. 8d,e). Interestingly, the ascending and poleward motions in $\mathrm{MJO}-\mathrm{C}$ are significantly stronger 

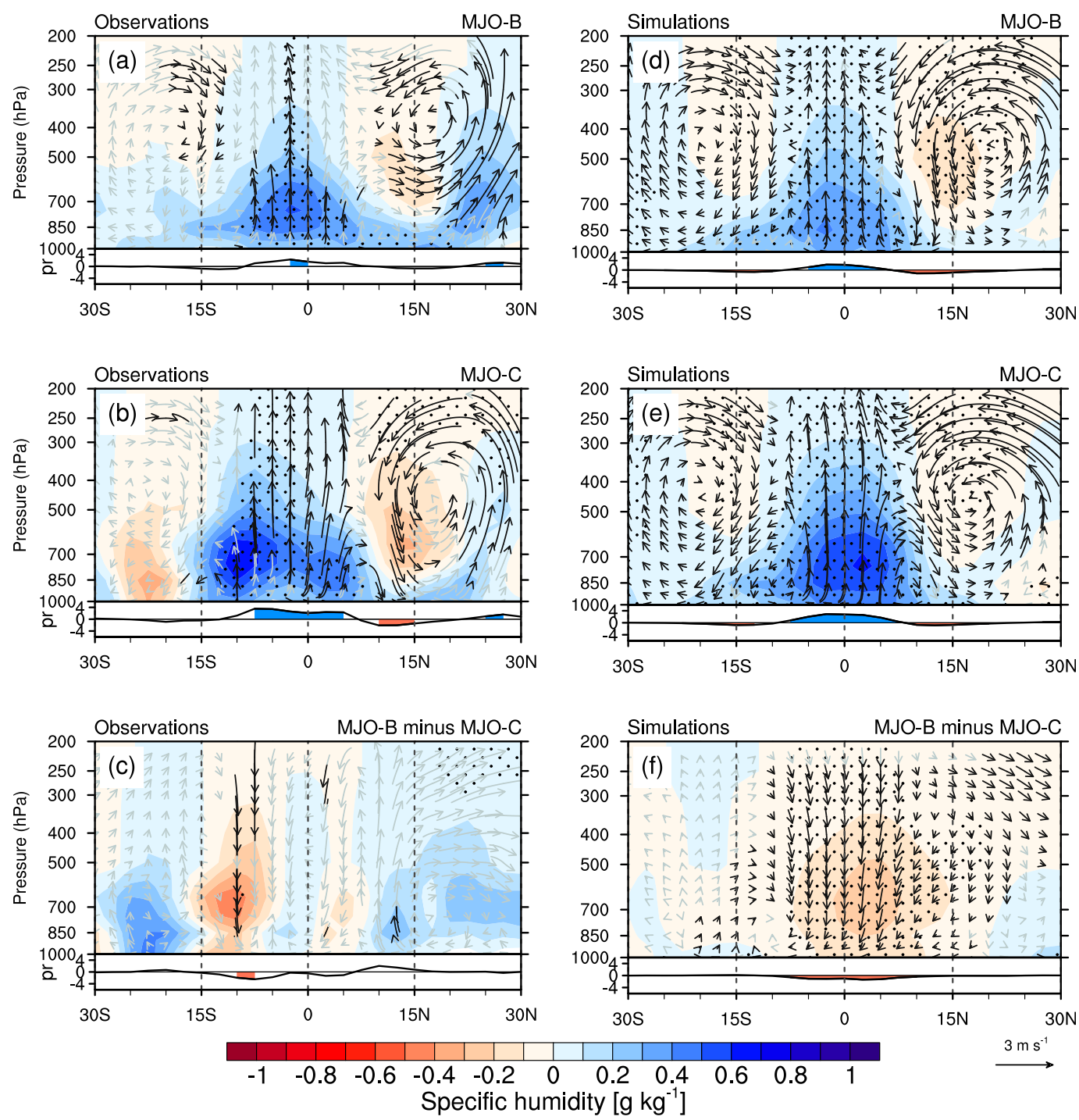

FIG. 8. Composites of vertical-meridional distributions of 20-100-day bandpass-filtered specific humidity anomalies (shadings, $\mathrm{g} \mathrm{kg}^{-1}$ ) and $v$ - $\omega$ wind anomalies (vectors) as well as corresponding precipitation anomalies (curves) averaged between $100^{\circ}$ and $140^{\circ} \mathrm{E}$ for (a),(d) MJO-B and (b),(e) MJO-C and (c),(f) their differences in the (left) observations and (right) simulations when the MJO tracks cross $90^{\circ} \mathrm{E}$. Vertical velocities are scaled by a factor of 100 to make them visible. Results that are significant at the $95 \%$ confidence level are marked by black arrows for wind vectors, stippling for specific humidity, and color for precipitation.

compared with MJO-B, suggesting stronger vertical and meridional advection of moisture in MJO-C than in MJO-B in the simulations (Fig. 8f). However, the vertical moisture advection is mostly canceled by the moisture sink (Kim et al. 2014), and the meridional moisture advection dominates the moisture advection processes (not shown). Our results suggest that the poleward advection of moisture from the equator is important for the MJO to overcome the barrier effect in the simulations, but no such evidence was found in the observations.
Another obvious difference between the observations and the simulations is the meridional location of the moisture anomaly east of the MJO convection. In the observations, the positive moisture anomalies of MJO-B are close to the equator, while they are centralized around $10^{\circ} \mathrm{S}$ for MJO-C (Figs. 8a,b). In the simulations, however, the positive moisture anomalies of both MJO-B and MJO-C tend to centralize around the equator (Figs. 8d,e). Indeed, it is similar for zonal wind and precipitation of the MJO (Fig. 6). In the observations, the precipitation of MJO-C tends to shift farther 

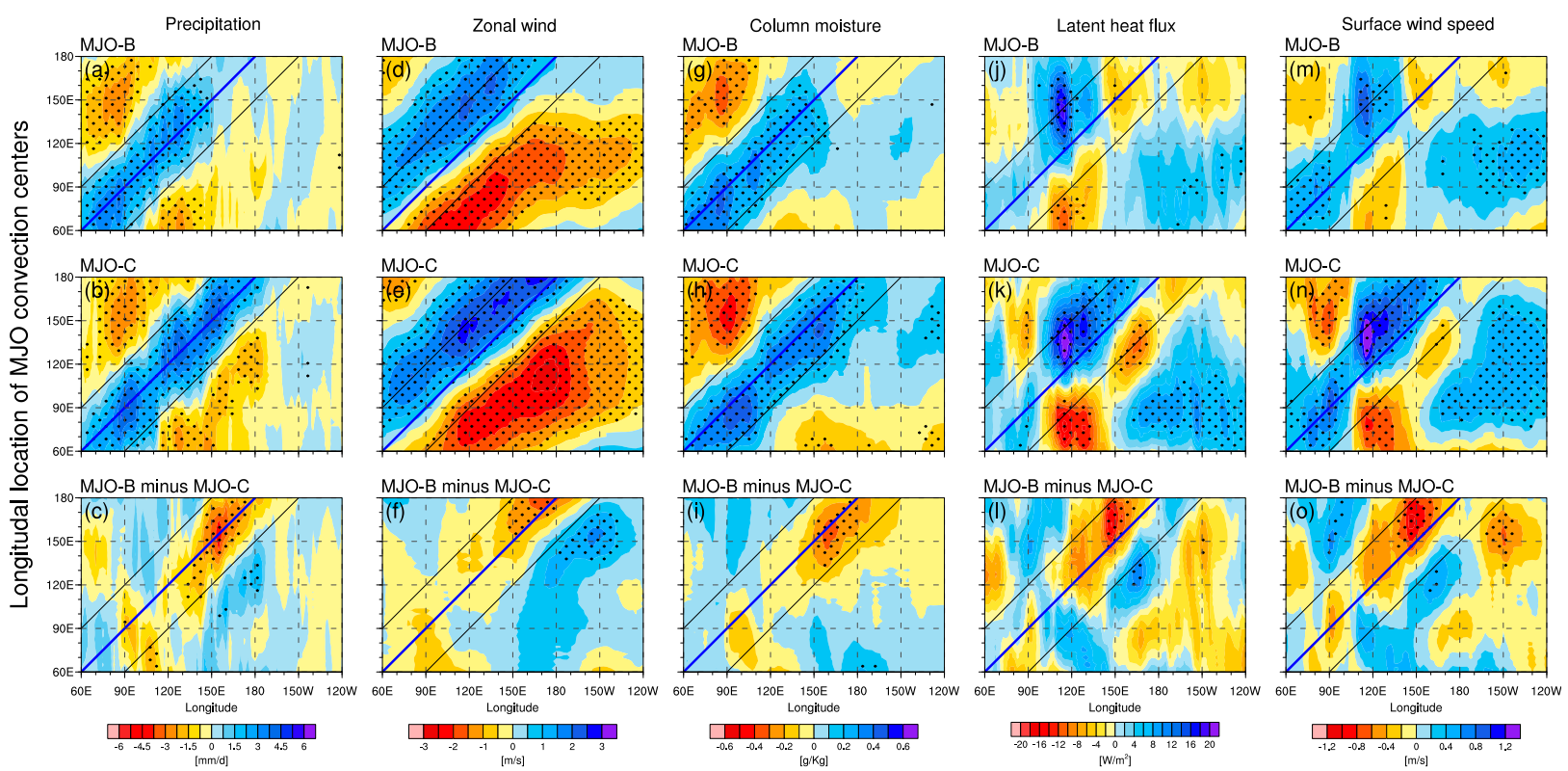

FIG. 9. Zonal distributions (abscissa) of 20-100-day bandpass-filtered (a)-(c) precipitation from TRMM, (d)-(f) 850-hPa zonal wind, and (g)-(i) column-integrated (1000-250 hPa) specific humidity from ERA-I and (j)-(l) sea surface latent heat fluxes and (m)-(o) sea surface wind speed from OAFlux averaged between $15^{\circ} \mathrm{S}$ and $15^{\circ} \mathrm{N}$ as functions of longitudes of MJO convection centers (ordinate) for (top) MJO-B and (middle) MJO-C, along with (bottom) their differences. Blue straight lines mark the track of the MJO convection center. The black straight lines mark the longitudinal range of $30^{\circ}$ on both sides of the track. Results that are significant at the $95 \%$ confidence level are stippled.

south compared with MJO-B. The low-level zonal wind anomalies associated with $\mathrm{MJO}-\mathrm{C}$ are located between $15^{\circ} \mathrm{S}$ and $5^{\circ} \mathrm{N}$ (Fig. 6b), but they are between $5^{\circ} \mathrm{S}$ and $15^{\circ} \mathrm{N}$ for MJO-B (Fig. 6a). This implies the importance of southward shift of MJO for its propagation across the MC during boreal winter in the observations (Wang and Rui 1990; Kim et al. 2017; Zhang and Ling 2017). However, the simulations cannot reproduce these differences, and both MJO-B and MJO-C tend to be equatorially symmetric in the simulations.

\section{c. Zonal structures}

We wish to explore when and where along the equator the two types of MJO events start to differ. For this, we compare zonal distributions of relevant variables as functions of the longitude of MJO convection centers (Fig. 9). A 20-100-day bandpass filter was applied to remove signals of the low- and high-frequency variabilities. The way to read Fig. 9 is very similar to reading a longitude-time lag regression diagram. If MJO events propagate at a constant speed, the ordinate (the longitude of MJO convection center) would be easily translated into time. For example, when the MJO convection center is located at $120^{\circ} \mathrm{E}$, the zonal distributions of precipitation anomalies (Figs. 9a,b) are given along the line parallel to the abscissa and intersecting with the ordinate at $120^{\circ} \mathrm{E}$. The positive anomalies around the convection center are expected from any convectional time-longitude composite or longitudetime lag regression. It is noted that the composites for MJO-B beyond $150^{\circ} \mathrm{E}$ were made along the extensions of the tracks. Although the convection of MJO-B events dissipated (under one standard deviation) east of $150^{\circ} \mathrm{E}$, their precipitation could still be positive but with much small values (Fig. 9a). An advantage of the composite based on longitudes of MJO convection centers over longitude-time lag regression is that the former does not suffer from decay in amplitude away from the single reference point in the latter as the MJO propagation speed varies.

In this comparison, we included precipitation (Figs. 9a-c), 850-hPa zonal wind (Figs. 9d-f), column-integrated (1000-250 hPa) specific humidity (Figs. 9g-i), sea surface latent heat flux (Figs. 9j-1), and sea surface wind speed (Figs. 9m-o). Significant differences between MJO-B and MJO-C events exist in all these variables but only when MJO convection centers are over the Pacific. They are results of the barrier effect of the MC. There is hardly any significant difference when MJO convection centers are over the Indian Ocean.

As MJO convection centers move over the MC (e.g., $120^{\circ} \mathrm{E}$ on the abscissa), a significant difference between the two types of MJO events first appears in precipitation (weaker for MJO-B). This is, however, not 

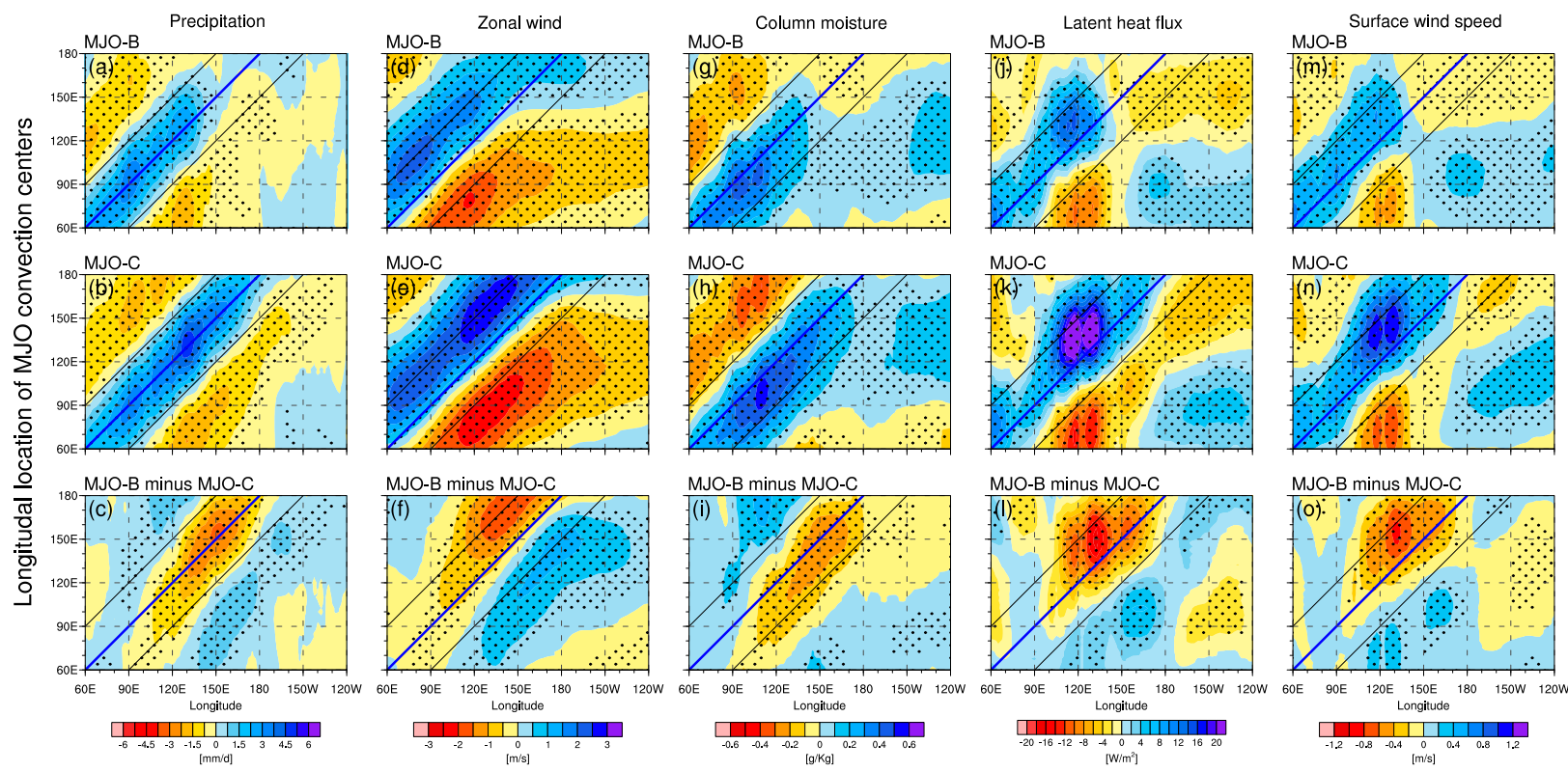

FIG. 10. As in Fig. 9, but for the simulations.

accompanied by other variables until later. Negative anomalies in humidity appear east of MJO convection centers when they are over the Indian Ocean $\left(60^{\circ}-90^{\circ} \mathrm{E}\right.$ at the ordinate), which is more obvious for MJO-C than MJO-B (Figs. 9g,h). This is in agreement with the result from Kim et al. (2014). But the difference between MJO-C and MJO-B is not significant (Fig. 9i). Dry anomalies brought by westward-propagating synoptic disturbances from central-western Pacific as a possible incidental barrier effect (Feng et al. 2015; DeMott et al. 2018) are not seen here.

The evolution of zonal distributions in sea surface latent heat fluxes along with the MJO based on the OAFlux product is as expected from the past observations (Krishnamurti et al. 1988; Zhang 1996; Araligidad and Maloney 2008): positive anomalies behind (west of) MJO convection centers and negative anomalies ahead (east of) for both MJO-B and MJO-C (Figs. 9j,k). There is no significant difference in surface latent heat flux between the two types of MJO events in the MC (Fig. 91). This implies that the MC barrier effect is not caused by reduced surface evaporation, as previously suggested (Maloney and Sobel 2004; Sobel et al. 2008, 2010). Interestingly, surface latent heat flux over a broad region of the Pacific when MJO convection centers are over the Indian Ocean is apparently larger for MJO-C than MJO-B (Figs. 9j,k), which is partially related to stronger surface wind speed (Figs. 9m,n). This is predicted by an MJO theory based on wind-induced surface heat exchange (WISHE; Fuchs and Raymond 2017). The differences are not significant (Figs. 91,o). Given the challenge of observing ocean surface fluxes (Brunke et al. 2011), the results based on OAFlux are confirmed by using the Japanese Ocean Flux Datasets with Use of Remote Sensing Observations (J-OFURO), version 3 (J-OFURO3; Tomita et al. 2019). They agree with each other qualitatively, with differences mainly in amplitudes (not shown).

The same comparisons of MJO-B and MJO-C from the simulations tell a different story. While the general features of eastward propagation of precipitation and other variables are similar to the observations, differences between the two types of the MJO are significant over a larger domain (Fig. 10). Significantly larger precipitation and stronger low-level zonal wind are present when MJO convection centers are over the Indian Ocean (Figs. 10c,f). These results alone suggest the strength of the MJO is a mechanism for overcoming the barrier effect. Moisture for MJO-B is significantly less than $\mathrm{MJO}-\mathrm{C}$ over the $\mathrm{MC}$ but higher over a broad region to the east (Fig. 10i). This is consistent with the result that the Rossby-wave circulation induced by suppressed convection east of the MJO is needed for MJO propagation through the MC (Kim et al. 2014). But the westward-advected dry air by synoptic perturbations as an incidental barrier effect (Feng et al. 2015; DeMott et al. 2018) is not present. Surface latent heat flux in the $\mathrm{MC}$ region is also significantly less for MJO-B than MJO-C (Fig. 101), which is partially due to the weaker surface wind speed (Fig. 10o), supporting the proposed idea that reduced surface evaporation over the $\mathrm{MC}$ is a mechanism leading to the MC barrier effect (Maloney 

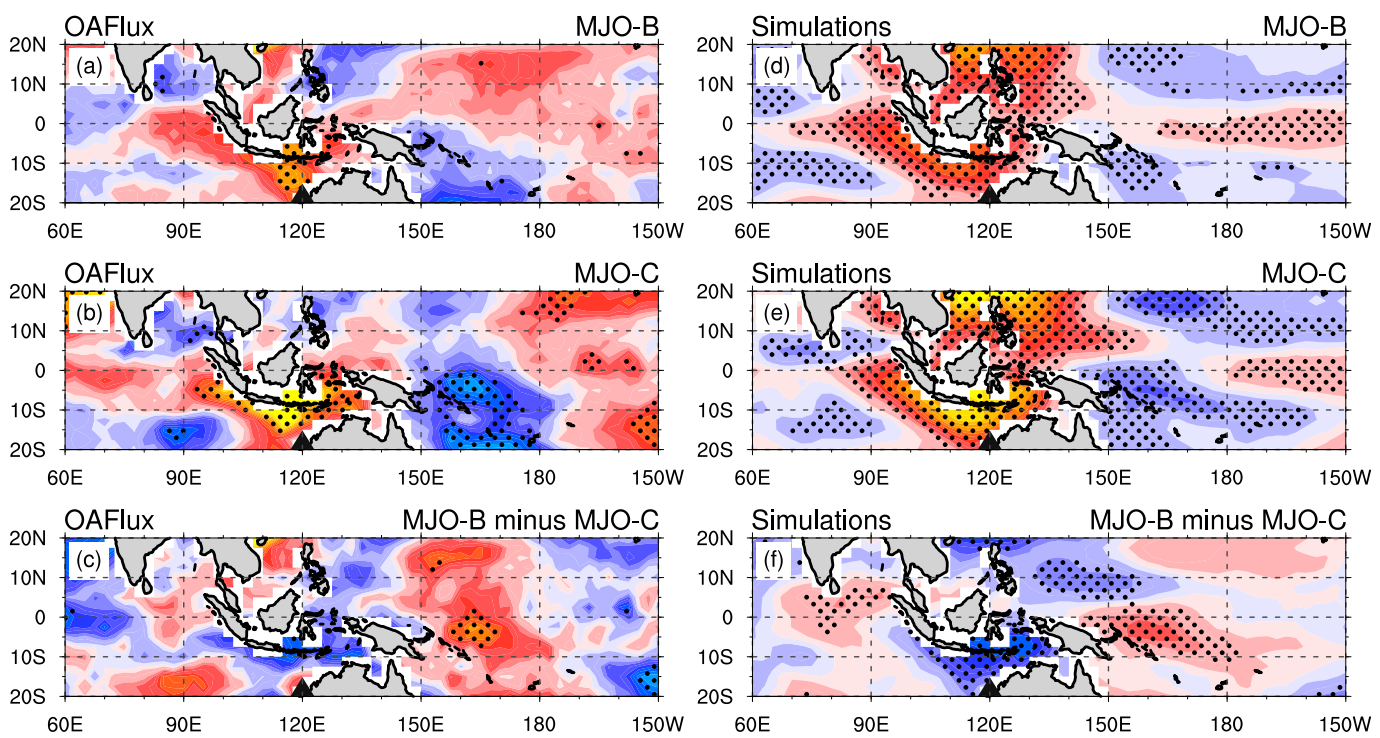

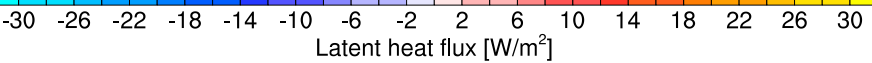

FIG. 11. Horizontal distributions of 20-100-day bandpass-filtered sea surface latent heat flux (shading) for (a),(d) MJO-B and (b),(e) MJO-C and (c),(f) and their differences from (left) OAFlux and (right) the simulations when $\mathrm{MJO}$ convection centers cross $120^{\circ} \mathrm{E}$ (marked by triangles). Results that are significant at the $95 \%$ confidence level are stippled.

and Sobel 2004; Sobel et al. 2008, 2010). But none of these can be confirmed by observations (Fig. 9).

To further examine how the simulations differ from the observations, we compare horizontal distributions of surface latent heat fluxes for the two types of the MJO in the observations and simulations (Fig. 11). In the observations (Figs. 11a-c), anomalies in surface latent heat fluxes are positive over the Indonesian Seas south of the equator when $\mathrm{MJO}$ convection centers are in the center of the $\mathrm{MC}\left(120^{\circ} \mathrm{E}\right)$. This is expected according to the preferred pathway of MJO propagation through the MC during boreal winter (Wang and Rui 1990; Kim et al. 2017; Zhang and Ling 2017). In this region, surface latent heat fluxes are apparently greater for MJO-C than MJO-B. But their difference is not significant. In the simulations (Figs. 11d-f), surface latent heat fluxes are substantially overestimated over a broad region from the southeastern Indian Ocean to the northwestern Pacific. This overestimation leads to a significant difference in surface latent heat fluxes between MJO-B and MJO-C.

\section{d. Precipitation over land and water}

It has been proposed that development of convection over water in the MC is a key process for the MJO to propagate through the MC (Zhang and Ling 2017). This is manifested by a shift from dominant MC precipitation over land through its strong diurnal cycle when MJO convection centers are over the Indian Ocean approaching the MC to dominant precipitation over water as the diurnal cycle over land is reduced when MJO convection centers are over the MC (Ichikawa and Yasunari 2007; Yokoi et al. 2017; Ling et al. 2019a). The simulation output does not allow an analysis of the diurnal cycle in precipitation. But this shift from landto water-dominant precipitation is present in the simulations (Fig. 12b). Also consistent with the observations, the difference between precipitation of MJO-C and MJO$\mathrm{B}$ is larger over water than over land after the MJO enters the MC. Even though the contrast between land and water precipitation is weaker in the simulations than in the observations, its existence in the simulations is intriguing given the poor representation of the land in the MC because of the coarse spatial resolution of the models (Baranowski et al. 2019).

The key process for MJO to overcome the barrier effect in the MAC3 mechanism (Ling et al. 2019a) is strong precipitation over land as the MJO convection center approaches the MC, which increases the soil moisture and reduces the diurnal amplitude of land convection subsequently and thus favors the development of nondiurnal convection over water. The precipitation over land of the $\mathrm{MC}$ is slightly stronger in MJO-C than MJO-B before, and weaker in MJO-C than MJO-B 
(a) TRMM

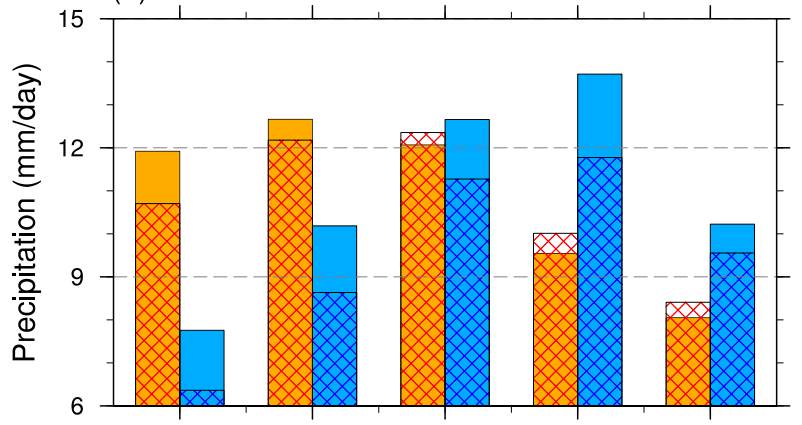

(b) Simulations

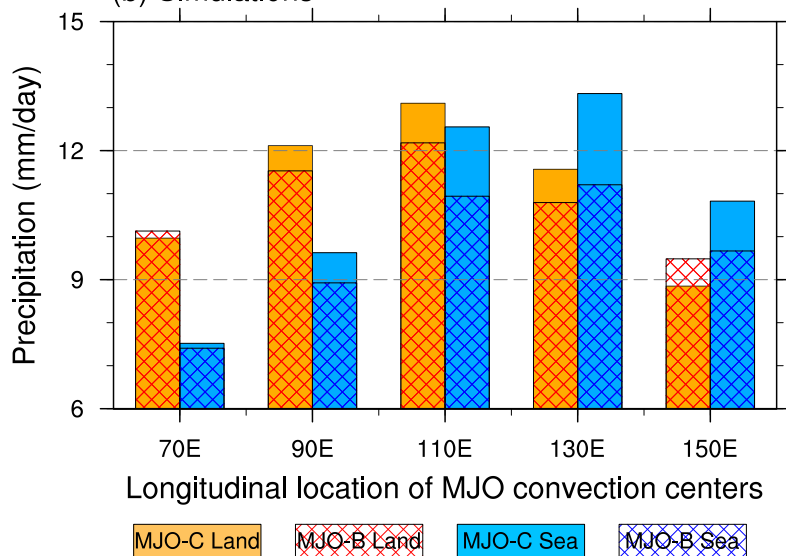

FIG. 12. Evolution of precipitation over land (bars with orange shading or red cross hatching) and sea (bars with light blue shading or blue cross hatching) over the Maritime Continent $\left(10^{\circ} \mathrm{S}-5^{\circ} \mathrm{N}\right.$, $100^{\circ}-150^{\circ} \mathrm{E}$ ) for MJO-B (cross hatching) and MJO-C (color shading) as functions of the longitudinal locations of $\mathrm{MJO}$ convection centers from (a) TRMM and (b) the simulations.

after, their convection centers enter the $\mathrm{MC}$ as expected (Fig. 12a). In the simulations, however, the precipitation over land of the MC is stronger in MJO-C when the $\mathrm{MJO}$ convection centers locate over the MC before they reach $150^{\circ} \mathrm{E}$ (Fig. 12b). These indicate that the MJO convection in the simulations might not mainly be carried by the precipitation over water as observed in observations (Zhang and Ling 2017; Ling et al. 2019a).

To further explore the discrepancies of the simulations, horizontal structures of precipitation and circulations between MJO-C and MJO-B in the observations and the simulations are compared when MJO convection centers are at $120^{\circ} \mathrm{E}$ (Fig. 13). In the observations, the convection signal of both MJO-B and MJO-C is carried by precipitation over water (Figs. 13a,b) while it is over both water and land in the simulations (Figs. 13d,e). The results confirm that the MJO convection is also carried by precipitation over land in the simulations. The results also suggest that the simulations cannot realistically reproduce the off-equator convection center of MJO-C as discussed in section $4 \mathrm{~b}$.

\section{e. Sea surface temperature}

It has been reported that SST over the MC and Pacific could impact the eastward propagation of MJO through the MC (Hirata et al. 2013; Kerns and Chen 2016; Zhang and Ling 2017; DeMott et al. 2018; Suematsu and Miura 2018; Zhou and Murtugudde 2020). Zhang and Ling (2017) found that there are significant warm SST anomalies in the MC water for MJO-C. Suematsu and Miura (2018) showed that warm low-frequency SST anomalies over the western-central Pacific are the precursor for MJO propagating through the MC, but no precursor was found in the intraseasonal time scale. The MJO activities along with its associated SST anomalies migrate to South Hemisphere seasonally during boreal winter (Zhang and Dong 2004; Zhang and Ling 2017). To better evaluate the role of SST in barrier effect, we compare the SST anomalies averaged over $15^{\circ} \mathrm{S}-0^{\circ}$ at different time scales between MJO-C and MJO-B in the observations and simulations when MJO convection centers are at $90^{\circ} \mathrm{E}$ (Fig. 14).

When only high-frequency signals were removed (by applying a low-pass filtering for $>20$ days), positive SST anomalies appear in the MC water for both MJO-B and $\mathrm{MJO}-\mathrm{C}$ and its negative anomalies over a broad area of the central and eastern Pacific Ocean (Fig. 14a). Positive anomalies in SST cover a broad area of the MC and western Pacific for MJO-C; these anomalies are, however, spatially confined over the western MC for MJO-B (Fig. 14a). On the intraseasonal time scale (20-100 days), significant positive SST anomalies over the whole MC and negative SST anomalies over the Indian Ocean were found for MJO-C same as Zhang and Ling (2017), while only significant positive SST anomalies over the western MC was identified for MJO-B (Fig. 14b). However, the difference between MJO-C and MJO-B is not significant except for a tiny longitudinal range.

The background SST ( $>100$ days) patterns for MJO-B and MJO-C change a lot (Fig. 14c). There are positive SST anomalies over the Indian Ocean in MJO-B and MJO-C. The background SST anomalies over the Pacific are not significant, nor are their differences, even though the negative SST anomalies in MJO-B suggest a preference for La Niña years for MJO-B. These results suggest that ENSO may impact the MJO propagation to a certain extent but by itself cannot determine whether MJO propagates through the MC. Indeed, 10 MJO-B events occur during La Niña years whereas only 4 MJO-B occur during El Niño years, but there are still 8 MJO-C in La Niña years and 5 MJO-C in El Niño years.

In the CMIP5 simulations, the observed patterns of SST anomalies are generally captured (Fig. 14, right 


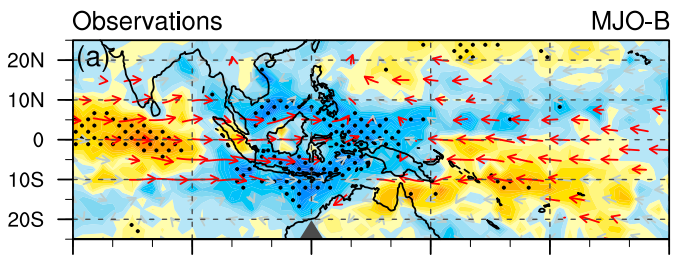

Observations

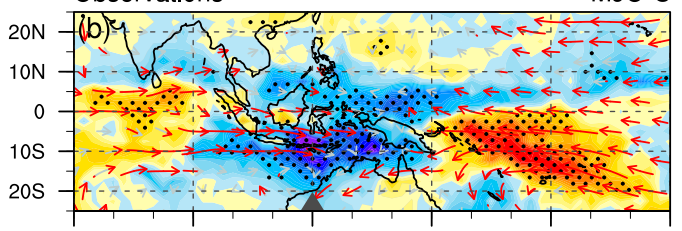

Observations

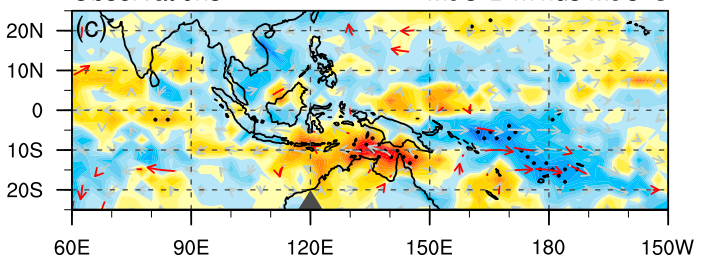

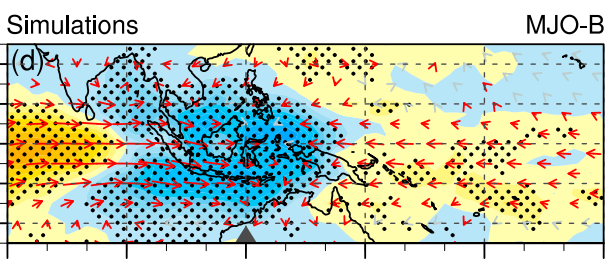
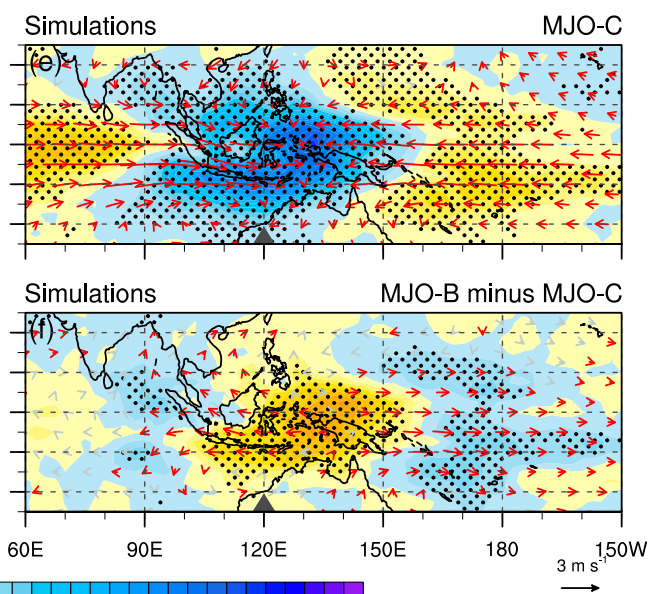

$\begin{array}{lllllllllllllllllllll}-10 & -9 & -8 & -7 & -6 & -5 & -4 & -3 & -2 & -1 & 0 & 1 & 2 & 3 & 4 & 5 & 6 & 7 & 8 & 9 & 10\end{array}$

FIG. 13. As in Fig. 6, but for when MJO convection centers cross $120^{\circ} \mathrm{E}$.

panels). The differences between $\mathrm{MJO}-\mathrm{C}$ and $\mathrm{MJO}-\mathrm{B}$ in the simulations suggest stronger intraseasonal SST induced by MJO-C (Fig. 14e), consistent with greater amplitude of MJO-C. Meanwhile, the background SST could be a main factor to modulate the barrier effect of the $\mathrm{MC}$ in the simulations, whereas no statistically significant evidence was found in the observations. However, the discrepancies between the simulations and observations may come from the small observed sample size.

\section{Summary and discussion}

We have diagnosed the barrier effect of the MC on MJO propagation in the observations and CMIP5 simulations based on individual MJO events identified by tracking their precipitation. All models simulate individual MJO events but underestimate the percentage of MJO events that propagate into the MC. The top $50 \%$ of the simulations produce MJO events with similar strength and barrier effect intensity as that in TRMM, while the bottom $50 \%$ significantly underestimate the strength of MJO and exaggerate the barrier effect intensity. These results do not come from a fraction of the simulations; they are commonly present in most of the top/bottom $50 \%$ of the simulations.

We have explored possible mechanisms for the barrier effect of the MC on MJO propagation in the observations and simulations through comparing the amplitudes of the MJO events, zonal- and meridionalvertical structures of their circulations, their precipitation over land and water of the MC, and SST between MJO events that cross the MC (MJO-C) and those that are blocked by the MC (MJO-B). Only the top $50 \%$ of the simulations that reproduce the MJO spectral signal and produce observed-like MJO events were used in the comparison. We treated all MJO events in the top 50\% of the simulations as a superensemble to explore whether the possible mechanisms for the barrier effect of the MC can be identified in both simulations and observations.

Diagnoses of the simulations alone would lead to conclusions that dry troposphere and reduced surface evaporation constitute the barrier effects; however, MJO strength can be a mechanism for overcoming the barrier effect. These conclusions cannot be drawn from the observations. Caution is, however, needed here. Conclusions from the observations may change when their sample size (number of identified MJO events) becomes larger.

There are several disagreements between the results from this and previous studies. They are possible roles of MJO strength, moisture processes including advected dry air by synoptic perturbations, and surface evaporation in the barrier effect. These disagreements come from different analysis methods and tools (observations, 

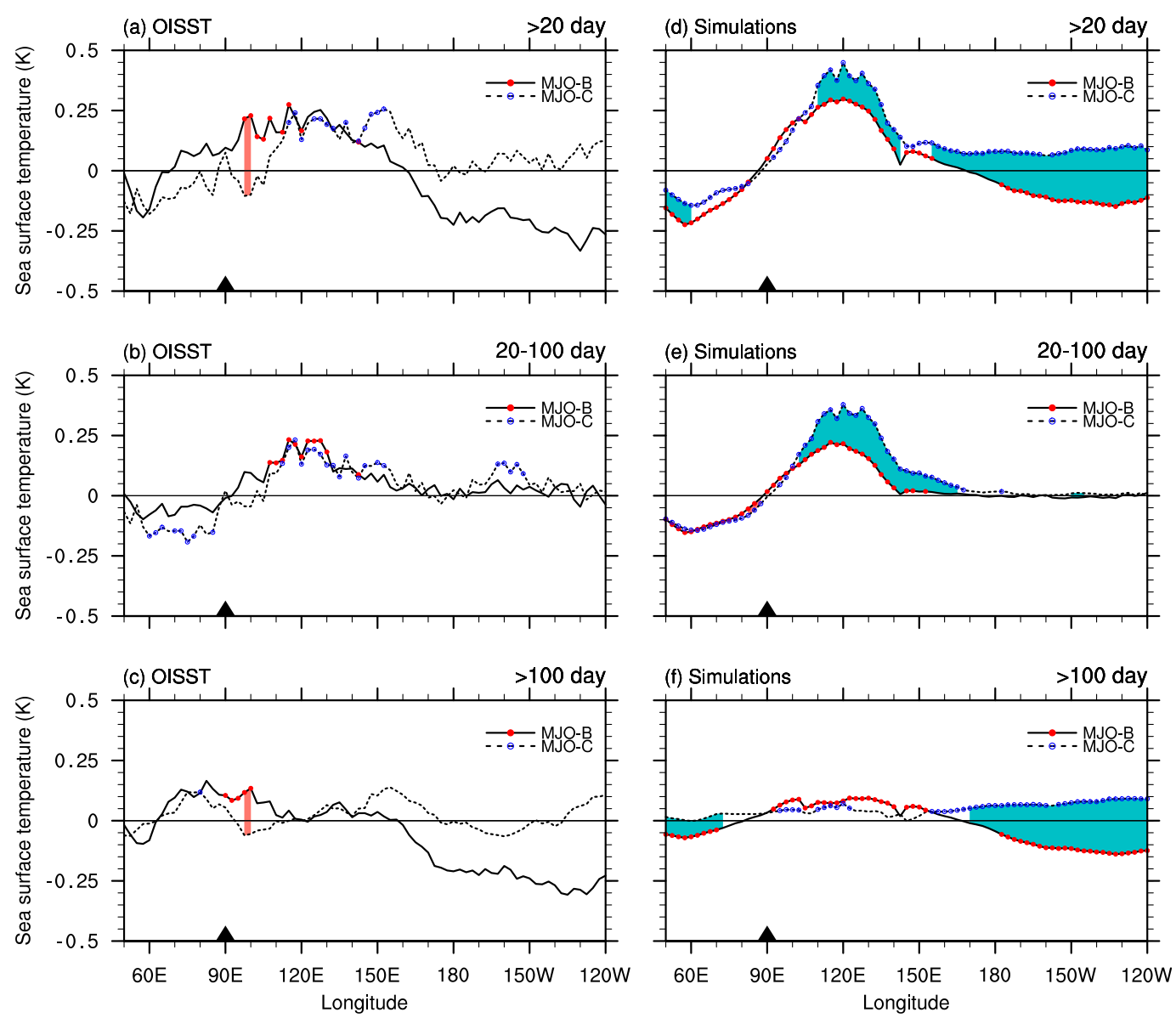

FIG. 14. Composites of (a),(d) 20-day low-pass, (b),(e) 20-100-day bandpass, and (c),(f) 100-day low-pass filtered SST anomalies averaged over $15^{\circ} \mathrm{S}-0^{\circ}$ for MJO-B (solid line) and MJO-C (dotted line) from (left) OISST and (right) the simulations when the $\mathrm{MJO}$ tracks cross $90^{\circ} \mathrm{E}$ (marked by solid triangles). Results that are significant at $95 \%$ confidence level are marked by red filled circles for MJO-B and blue open circles for MJO-C, and color shading for their difference.

model simulations, theoretical approaches). Sorting out these disagreements requires vigorous significance tests of statistical results.

The most evident consistency between the observations and simulations is the differential shifts between land versus water precipitation in the $\mathrm{MC}$ region for MJO-C and MJO-B events. Both observations and simulations demonstrate a shift of precipitation from land to water in the MC as MJO convection centers move from the Indian Ocean through the $\mathrm{MC}$, and this shift is much greater for MJO-C and MJO-B, even though this shift is underestimated in the simulations.

It is unlikely that the models can produce realistic diurnal cycle over land (Neale and Slingo 2003; Wang and Sobel 2017; Yang et al. 2019) and mesoscale convective systems (MCSs) over water. Yet, they still reproduced the observed contrast between $\mathrm{MC}$ precipitation over land and water and the difference between MJO-C and MJO-B as their convection centers propagate through the MC. From a model-centric viewpoint, this may disprove the MAC3 hypothesis that diurnal convection over land and development of MCSs over water are keys to the barrier effect of the MC (Ling et al. 2019a). From an observation-centric viewpoint (held by the authors of this article), this suggests that the models get the right results for wrong reasons. In any case, the consistent results from the observations and simulations support the notion that the contrast between land and water precipitation in the MC region is essential to the barrier effect. It is worth further investigation on this using high-resolution models that can adequately resolve both land diurnal convection and MCSs over water in the MC region (e.g., Sato et al. 2009).

In the observations, the convection and circulations associated with MJO-C located farther south compared with MJO-B. This implies the importance of a southward 
shift of the MJO over the ocean for its propagation across the MC during boreal winter (Wang and Rui 1990; Kim et al. 2017; Zhang and Ling 2017). In the simulations, however, the convection and circulations in both MJO-C and MJO-B tend to locate over the equator. These results suggest that the simulations cannot realistically represent the meridional location of MJO convection center, which might be related to their discrepancies in reproducing the physical processes of convection over the MC (Neale and Slingo 2003; Yang et al. 2019).

There is a concern that the conclusions based on the simulated MJO events from the top $50 \%$ of the simulations as a superensemble may not equally apply to each individual model. We have conducted the same analyses for each model, and the conclusions can also be applied to most individual models even though the sample sizes become much smaller. Our results highlight that even if the models can reproduce the MJO events with similar statistics as in the observations, they are not necessarily able to reproduce the mechanisms for the barrier effect of the MC on MJO propagation. This study suggests that caution should be taken when using the models to understand the physical processes of the barrier effect because their mechanisms of barrier effect might be different from the observations.

We have examined the statistics of the simulated MJO events by a limited number of CMIP6 models using the same tracking method as in this study, but the improvement is imperceptible compared with those of CMIP5. We do not expect significant improvement in CMIP6 simulations, but this might be worth checking for the higherresolution models when CMIP6 outputs are fully available.

Acknowledgments. This research was sponsored by the National Key R\&D Program of China through Grants 2018YFC1505901 and 2018YFA0606203; the National Nature Science Foundation of China through Grants 41922035, 41575062, and 41520104008; and the Key Research Program of Frontier Sciences of CAS through Grant QYZDB-SSW-DQC017 (authors Chen, Ling, Li, and Yuanwen Zhang). The first author acknowledges support from the China Scholarship Council (CSC) Grant 201804910705 and thanks the University of Washington for hosting his two years' visit, during which period this study was conducted. PMEL Contribution Number is 5026 (author Chidong Zhang).

\section{REFERENCES}

Adames, Á. F., and J. M. Wallace, 2014: Three-dimensional structure and evolution of the vertical velocity and divergence fields in the MJO.J. Atmos. Sci., 71, 4661-4681, https://doi.org/ 10.1175/JAS-D-14-0091.1.
— and - 2015: Three-dimensional structure and evolution of the moisture field in the MJO. J. Atmos. Sci., 72, 3733-3754, https://doi.org/10.1175/JAS-D-15-0003.1.

Ahn, M.-S., D. Kim, K. R. Sperber, I.-S. Kang, E. D. Maloney, D. E. Waliser, and H. H. Hendon, 2017: MJO simulation in CMIP5 climate models: MJO skill metrics and processoriented diagnosis. Climate Dyn., 49, 4023-4045, https:// doi.org/10.1007/s00382-017-3558-4.

Araligidad, N. M., and E. D. Maloney, 2008: Wind-driven latent heat flux and the intraseasonal oscillation. Geophys. Res. Lett., 35, L04815, https://doi.org/10.1029/2007GL032746.

Baranowski, D. B., D. E. Waliser, X. Jiang, J. A. Ridout, and M. K. Flatau, 2019: Contemporary GCM fidelity in representing the diurnal cycle of precipitation over the maritime continent. J. Geophys. Res. Atmos., 124, 747-769, https://doi.org/10.1029/ 2018JD029474.

Brunke, M. A., Z. Wang, X. B. Zeng, M. Bosilovich, and C. L. Shie, 2011: An assessment of the uncertainties in ocean surface turbulent fluxes in 11 reanalysis, satellite-derived, and combined global datasets. J. Climate, 24, 5469-5493, https:// doi.org/10.1175/2011JCLI4223.1.

Chen, G., and B. Wang, 2018: Effects of enhanced front walker cell on the eastward propagation of the MJO. J. Climate, 31, 77197738, https://doi.org/10.1175/JCLI-D-17-0383.1.

Dee, D. P., and Coauthors, 2011: The ERA-Interim reanalysis: Configuration and performance of the data assimilation system. Quart. J. Roy. Meteor. Soc., 137, 553-597, https://doi.org/ 10.1002/qj.828.

DeMott, C. A., B. O. Wolding, E. D. Maloney, and D. A. Randall, 2018: Atmospheric mechanisms for MJO decay over the Maritime Continent. J. Geophys. Res. Atmos., 123, 5188-5204, https://doi.org/10.1029/2017JD026979.

Feng, J., T. Li, and W. Zhu, 2015: Propagating and nonpropagating MJO events over Maritime Continent. J. Climate, 28, 8430 8449, https://doi.org/10.1175/JCLI-D-15-0085.1.

Fuchs, Ž., and D. J. Raymond, 2017: A simple model of intraseasonal oscillations. J. Adv. Model. Earth Syst., 9, 1195-1211, https://doi.org/10.1002/2017MS000963.

Gianotti, R. L., D. Zhang, and E. A. Eltahir, 2012: Assessment of the Regional Climate Model version 3 over the Maritime Continent using different cumulus parameterization and land surface schemes. J. Climate, 25, 638-656, https://doi.org/ 10.1175/JCLI-D-11-00025.1.

Hagos, S. M., C. Zhang, Z. Feng, C. D. Burleyson, C. De Mott, B. Kerns, J. J. Benedict, and M. N. Martini, 2016: The impact of the diurnal cycle on the propagation of Madden-Julian oscillation convection across the Maritime Continent. J. Adv. Model. Earth Syst., 8, 1552-1564, https://doi.org/10.1002/ 2016MS000725.

Hirata, F. E., P. J. Webster, and V. E. Toma, 2013: Distinct manifestations of austral summer tropical intraseasonal oscillations. Geophys. Res. Lett., 40, 3337-3341, https://doi.org/ 10.1002/grl.50632.

Hsu, H.-H., and M. Y. Lee, 2005: Topographic effects on the eastward propagation and initiation of the Madden-Julian oscillation. J. Climate, 18, 795-809, https://doi.org/10.1175/ JCLI-3292.1.

Huffman, G. J., and Coauthors, 2007: The TRMM Multisatellite Precipitation Analysis (TMPA): Quasi-global, multiyear, combined-sensor precipitation estimates at fine scales. J. Hydrometeor., 8, 38-55, https://doi.org/10.1175/JHM560.1.

Hung, M., J. Lin, W. Wang, D. Kim, T. Shinoda, and S. J. Weaver, 2013: MJO and convectively coupled equatorial waves simu- 
lated by CMIP5 climate models. J. Climate, 26, 6185-6214, https://doi.org/10.1175/JCLI-D-12-00541.1.

Ichikawa, H., and T. Yasunari, 2007: Propagating diurnal disturbances embedded in the Madden-Julian oscillation. Geophys. Res. Lett., 34, L18811, https://doi.org/10.1029/ 2007 GL030480.

Inness, P. M., and J. M. Slingo, 2006: The interaction of the Madden-Julian oscillation with the Maritime Continent in a GCM. Quart. J. Roy. Meteor. Soc., 132, 1645-1667, https:// doi.org/10.1256/qj.05.102.

Jiang, X., and Coauthors, 2015: Vertical structure and physical processes of the Madden-Julian oscillation: Exploring key model physics in climate simulations. J. Geophys. Res. Atmos., 120, 4718-4748, https://doi.org/10.1002/2014JD022375.

Kerns, B. W., and S. S. Chen, 2016: Large-scale precipitation tracking and the MJO over the Maritime Continent and IndoPacific warm pool. J. Geophys. Res. Atmos., 121, 8755-8776, https://doi.org/10.1002/2015JD024661.

Kiladis, G. N., K. H. Straub, and P. T. Haertel, 2005: Zonal and vertical structure of the Madden-Julian oscillation. J. Atmos. Sci., 62, 2790-2809, https://doi.org/10.1175/JAS3520.1.

—, J. Dias, K. H. Straub, M. C. Wheeler, S. N. Tulich, K. Kikuchi, K. M. Weickmann, and M. J. Ventrice, 2014: A comparison of OLR and circulation-based indices for tracking the MJO. Mon. Wea. Rev., 142, 1697-1715, https://doi.org/10.1175/MWRD-13-00301.1.

Kim, D., and Coauthors, 2009: Application of MJO simulation diagnostics to climate models. J. Climate, 22, 6413-6436, https://doi.org/10.1175/2009JCLI3063.1.

_, J. Kug, and A. H. Sobel, 2014: Propagating versus nonpropagating Madden-Julian oscillation events. J. Climate, 27, 111-125, https://doi.org/10.1175/JCLI-D-13-00084.1.

—, H. Kim, and M. I. Lee, 2017: Why does the MJO detour the Maritime Continent during austral summer? Geophys. Res. Lett., 44, 2579-2587, https://doi.org/10.1002/2017GL072643.

Kim, H., F. Vitart, and D. E. Waliser, 2018: Prediction of the Madden-Julian oscillation: A review. J. Climate, 31, 94259443, https://doi.org/10.1175/JCLI-D-18-0210.1.

Krishnamurti, T. N., D. K. Oosterhof, and A. V. Mehta, 1988: Air-sea interaction on the time scale of 30 to 50 days. J. Atmos. Sci., 45, 1304-1322, https://doi.org/10.1175/15200469(1988)045<1304:AIOTTS>2.0.CO;2.

Ling, J., P. Bauer, P. Bechtold, A. Beljaars, R. Forbes, F. Vitart, M. Ulate, and C. Zhang, 2014: Global versus local MJO forecast skill of the ECMWF model during DYNAMO. Mon. Wea. Rev., 142, 2228-2247, https://doi.org/10.1175/MWR-D13-00292.1.

-, C. Zhang, S. Wang, and C. Li, 2017: A new interpretation of the ability of global models to simulate the MJO. Geophys. Res. Lett., 44, 5798-5806, https://doi.org/10.1002/ 2017GL073891.

,,-- R. Joyce, P.-P. Xie, and G. Chen, 2019a: Possible role of the diurnal cycle in land convection in the barrier effect on the MJO by the Maritime Continent. Geophys. Res. Lett., 46, 3001-3011, https://doi.org/10.1029/2019GL081962.

— , Y. Zhao, and G. Chen, 2019b: Barrier effect on MJO propagation by the Maritime Continent in the MJO Task Force/ GEWEX atmospheric system study models. J. Climate, 32, 5529-5547, https://doi.org/10.1175/JCLI-D-18-0870.1.

Liu, P., Q. Zhang, C. Zhang, Y. Zhu, M. Khairoutdinov, H. M. Kim, C. Schumacher, and M. Zhang, 2016: A revised real-time multivariate MJO index. Mon. Wea. Rev., 144, 627-642, https://doi.org/10.1175/MWR-D-15-0237.1.
Love, B. S., A. J. Matthews, and G. M. S. Lister, 2011: The diurnal cycle of precipitation over the Maritime Continent in a highresolution atmospheric model. Quart. J. Roy. Meteor. Soc., 137, 934-947, https://doi.org/10.1002/qj.809.

Madden, R. A., and P. R. Julian, 1971: Detection of a 40-50-day oscillation in zonal wind in tropical Pacific. J. Atmos. Sci., 28, 702-708, https://doi.org/10.1175/1520-0469(1971)028<0702: DOADOI $>2.0 . \mathrm{CO} ; 2$.

$\longrightarrow$, and - 1972: Description of global-scale circulation cells in tropics with a 40-50 day period. J. Atmos. Sci., 29, 1109-1123, https://doi.org/10.1175/1520-0469(1972)029<1109:DOGSCC > 2.0.CO;2.

Maloney, E. D., and A. H. Sobel, 2004: Surface fluxes and ocean coupling in the tropical intraseasonal oscillation. J. Climate, 17, 4368-4386, https://doi.org/10.1175/JCLI-3212.1.

Neale, R., and J. Slingo, 2003: The Maritime Continent and its role in the global climate: A GCM study. J. Climate, 16, 834-848, https://doi.org/10.1175/1520-0442(2003)016<0834:TMCAIR > 2.0.CO;2.

Oliver, E. C. J., 2016: Blind use of reanalysis data: Apparent trends in Madden-Julian oscillation activity driven by observational changes. Int. J. Climatol., 36, 3458-3468, https://doi.org/ 10.1002/joc. 4568 .

Reynolds, R. W., T. M. Smith, C. Liu, D. B. Chelton, K. S. Casey, and M. G. Schlax, 2007: Daily high-resolution-blended analyses for sea surface temperature. J. Climate, 20, 5473-5496, https://doi.org/10.1175/2007JCLI1824.1.

Ruppert, J. H., and C. Hohenegger, 2018: Diurnal circulation adjustment and organized deep convection. J. Climate, 31, 48994916, https://doi.org/10.1175/JCLI-D-17-0693.1.

Sato, T., H. Miura, M. Satoh, Y. N. Takayabu, and Y. Wang, 2009: Diurnal cycle of precipitation in the tropics simulated in a global cloud-resolving model. J. Climate, 22, 4809-4826, https://doi.org/10.1175/2009JCLI2890.1.

Seo, K. H., W. Wang, J. Gottschalck, Q. Zhang, J.-K. E. Schemm, W. R. Higgins, and A. Kumar, 2009: Evaluation of MJO forecast skill from several statistical and dynamical forecast models. J. Climate, 22, 2372-2388, https://doi.org/10.1175/ 2008JCLI2421.1.

Shinoda, T., H. H. Hendon, and J. Glick, 1998: Intraseasonal variability of surface fluxes and sea surface temperature in the tropical western Pacific and Indian Oceans. J. Climate, 11, 1685-1702, https://doi.org/10.1175/1520-0442(1998)011<1685: IVOSFA $>2.0 . \mathrm{CO} ; 2$.

Sobel, A., E. Maloney, G. Bellon, and M. F. Dargan, 2008: The role of surface heat fluxes in tropical intraseasonal oscillations. Nat. Geosci., 1, 653-657, https://doi.org/10.1038/ngeo312.

,,,--- and D. Frierson, 2010: Surface fluxes and tropical intraseasonal variability: A reassessment. J. Adv. Model. Earth Syst., 2 (1), https://doi.org/10.3894/JAMES.2010.2.2.

Sperber, K. R., 2003: Propagation and the vertical structure of the Madden-Julian oscillation. Mon. Wea. Rev., 131, 3018-3037, https://doi.org/10.1175/1520-0493(2003)131<3018:PATVSO> 2.0.CO;2.

Straub, K. H., 2013: MJO initiation in the real-time multivariate MJO index. J. Atmos. Sci., 26, 1130-1151, https://doi.org/ 10.1175/JCLI-D-12-00074.1.

Suematsu, T., and H. Miura, 2018: Zonal SST difference as a potential environmental factor supporting the longevity of the Madden-Julian oscillation. J. Climate, 31, 7549-7564, https:// doi.org/10.1175/JCLI-D-17-0822.1.

Tan, H., P. Ray, B. S. Barrett, M. Tewari, and M. W. Moncrieff, 2020: Role of topography on the MJO in the Maritime 
Continent: A numerical case study. Climate Dyn., https:// doi.org/10.1007/s00382-018-4275-3, in press.

Taylor, K. E., R. J. Stouffer, and G. A. Meehl, 2012: An overview of CMIP5 and the experiment design. Bull. Amer. Meteor. Soc., 93, 485-498, https://doi.org/10.1175/BAMS-D-11-00094.1.

Tomita, H., T. Hihara, S. Kato, M. Kubota, and K. Kutsuwada, 2019: An introduction to J-OFURO3, a third-generation Japanese ocean flux data set using remote-sensing observations. J. Oceanogr., 75, 171-194, https://doi.org/10.1007/ s10872-018-0493-x.

Tseng, W.-L., H.-H. Hsu, N. Keenlyside, C.-W. J. Chang, B.-J. Tsuang, C.-Y. Tu, and L.-C. Jiang, 2017: Effects of surface orography and land-sea contrast on the Madden-Julian oscillation in the Maritime Continent: A numerical study using ECHAM5-SIT. J. Climate, 30, 9725-9741, https://doi.org/ 10.1175/JCLI-D-17-0051.1.

Vitart, F., S. Woolnough, M. A. Balmaseda, and A. M. Tompkins, 2007: Monthly forecast of the Madden-Julian oscillation using a coupled GCM. Mon. Wea. Rev., 135, 2700-2715, https://doi.org/10.1175/MWR3415.1.

Wang, B., and H. Rui, 1990: Dynamics of coupled moist KelvinRossby waves on an equatorial b-plane. J. Atmos. Sci., 47, 397413, https://doi.org/10.1175/1520-0469(1990)047<0397:DOTCMK> 2.0.CO;2.

Wang, L., T. Li, E. D. Maloney, and B. Wang, 2017: Fundamental causes of propagating and nonpropagating MJOs in MJOTF/ GASS models. J. Climate, 30, 3743-3769, https://doi.org/ 10.1175/JCLI-D-16-0765.1.

Wang, S., and A. H. Sobel, 2017: Factors controlling rain on small tropical islands: Diurnal cycle, large-scale wind speed, and topography. J. Atmos. Sci., 74, 3515-3532, https://doi.org/ 10.1175/JAS-D-16-0344.1.

- - , F. Zhang, Y. Q. Sun, Y. Yue, and L. Zhou, 2015 Regional simulation of the October and November MJO events observed during the CINDY/DYNAMO field campaign at gray zone resolution. J. Climate, 28, 2097-2119, https://doi.org/10.1175/JCLI-D-14-00294.1.

- - - M. K. Tippett, and F. Vitart, 2019: Prediction and predictability of tropical intraseasonal convection: Seasonal dependence and the Maritime Continent prediction barrier. Climate Dyn., 52, 6015-6031, https://doi.org/10.1007/s00382018-4492-9.

Wang, W., M. P. Hung, S. Weaver, A. Kumar, and X. Fu, 2014: MJO prediction in the NCEP Climate Forecast System version 2. Climate Dyn., 42, 2509-2520, https://doi.org/10.1007/ s00382-013-1806-9.

Wheeler, M. C., and G. N. Kiladis, 1999: Convectively coupled equatorial waves: Analysis of clouds and temperature in the wavenumber-frequency domain. J. Atmos. Sci., 56, 374-399, https://doi.org/10.1175/1520-0469(1999)056<0374:CCEWAO> 2.0.CO;2.

, and H. H. Hendon, 2004: An all-season real-time multivariate MJO index: Development of an index for monitoring and prediction. Mon. Wea. Rev., 132, 1917-1932, https://doi.org/ 10.1175/1520-0493(2004)132<1917:AARMMI>2.0.CO;2.

Wu, C. H., and H. H. Hsu, 2009: Topographic influence on the MJO in the Maritime Continent. J. Climate, 22, 5433-5448, https:// doi.org/10.1175/2009JCLI2825.1.

Yang, S., T. Zhang, Z. Li, and S. Dong, 2019: Climate variability over the Maritime Continent and its role in global climate variation: A review. J. Meteor. Res., 33, 993-1015, https:// doi.org/10.1007/s13351-019-9025-x.

Yokoi, S., S. Mori, M. Katsumata, B. Geng, K. Yasunaga, F. Syamsudin, N. Nurhayati, and K. Yoneyama, 2017: Diurnal cycle of precipitation observed in the western coastal area of Sumatra Island: Offshore preconditioning by gravity waves. Mon. Wea. Rev., 145, 3745-3761, https://doi.org/10.1175/ MWR-D-16-0468.1.

Yu, L., X. Jin, and R. A. Weller, 2008: Multidecade global flux datasets from the Objectively Analyzed Air-Sea Fluxes (OAFlux) project: Latent and sensible heat fluxes, ocean evaporation, and related surface meteorological variables. Woods Hole Oceanographic Institute OAFlux Project Tech. Rep. OA-2008-01, 64 pp., http://oaflux.whoi.edu/pdfs/ OAFlux_TechReport_3rd_release.pdf.

Zhang, C., 1996: Atmospheric intraseasonal variability at the surface in the tropical western Pacific Ocean. J. Atmos. Sci., 53, 739-758, https://doi.org/10.1175/1520-0469(1996)053<0739: AIVATS $>2.0 . \mathrm{CO} ; 2$.

2005: Madden-Julian oscillation. Rev. Geophys., 43, RG2003, https://doi.org/10.1029/2004RG000158.

, 2013: Madden-Julian oscillation: Bridging weather and climate. Bull. Amer. Meteor. Soc., 94, 1849-1870, https://doi.org/ 10.1175/BAMS-D-12-00026.1.

- and H. H. Hendon, 1997: Propagating and standing components of the intraseasonal oscillation in tropical convection. J. Atmos. Sci., 54, 741-752, https://doi.org/10.1175/15200469(1997)054<0741:PASCOT>2.0.CO;2.

and M. Dong, 2004: Seasonality in the Madden-Julian oscillation. J. Climate, 17, 3169-3180, https://doi.org/10.1175/ 1520-0442(2004)017<3169:SITMO > 2.0.CO;2.

, and J. Ling, 2017: Barrier effect of the Indo-Pacific Maritime Continent on the MJO: Perspectives from tracking MJO precipitation. J. Climate, 30, 3439-3459, https://doi.org/ 10.1175/JCLI-D-16-0614.1.

M. Dong, S. Gualdi, H. H. Hendon, E. D. Maloney, A. Marshall, K. R. Sperber, and W. Wang, 2006: Simulations of the Madden-Julian oscillation in four pairs of coupled and uncoupled global models. Climate Dyn., 27, 573-592, https:// doi.org/10.1007/s00382-006-0148-2.

Zhou, L., and R. Murtugudde, 2020: Oceanic impacts on MJOs detouring near the Maritime Continent. J. Climate, 33, 23712388, https://doi.org/10.1175/JCLI-D-19-0505.1.

Zhu, J., W. Wang, and A. Kumar, 2017: Simulations of MJO propagation across the Maritime Continent: Impacts of SST feedback. J. Climate, 30, 1689-1704, https://doi.org/10.1175/ JCLI-D-16-0367.1. 